NISTIR 7821

PFTII report

\title{
Plain and Rolled Fingerprint Matching with Proprietary Templates
}

\author{
Su Lan Cheng \\ Gregory Fiumara \\ Craig Watson
}




\title{
PFTII report Plain and Rolled Fingerprint Matching with Proprietary Templates
}

\author{
Su Lan Cheng \\ Gregory Fiumara \\ Craig Watson
}

Information Technology laboratory

Information Access Division

October 2011

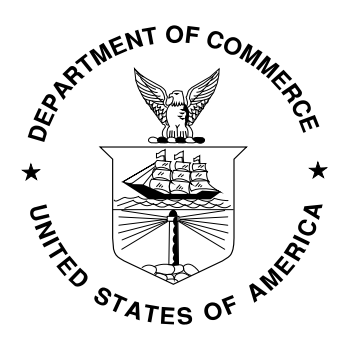

U.S. Department of Commerce John E. Bryson, Secretary 


\title{
PFTII report: Plain and Rolled Fingerprint Matching with Proprietary Templates
}

\begin{abstract}
This report is an extension of the "Two Finger Matching with Vendor SDK ${ }^{1}$ Matches" [1] which evaluated the accuracy of matching two plain impression fingerprints (right index and left index) with proprietary fingerprint templates. This study is based on National Institute of Standards and Technology's (NIST) ongoing proprietary fingerprint template (PFTII) program (http://www.nist.gov/it//iad/ig/pftii.cfm) which evaluates matching two plain index fingers of two datasets and six fingers (both thumbs, index fingers, and middle fingers) of one dataset. The fingerprint matches are performed between different types of print impressions: plain vs. plain images (p2p), plain vs. rolled images (p2r), and rolled vs. rolled images ( $2 r)$. The proprietary template size, the timings for template extractions, and comparisons are examined and summarized.
\end{abstract}

\section{Introduction}

Prior to PFTII, the proprietary fingerprint template (PFT) evaluations were performed to measure the accuracy of two-finger matching verification systems [1] for two plain impression fingerprints. In another study [2], the performance from matching images of plain impression fingerprints, (referred in this report as "plain"), and rolled impression fingerprints, (referred in this report as "rolled"), of thumbs, index, middle, ring and little fingers were shown for the participant's SDK matchers. In [3], studies on fingerprint matching accuracy have been researched on plain to rolled fingerprint matching using the NIST Algorithmic Test Bed (ATB $)^{2}$ on various datasets. However in [2, 3], the dataset size for the plain to rolled comparison were significantly smaller.

The PFTII evaluation expands the size of both gallery and probe sets from PFT. Two of the fingerprints datasets from the PFT evaluation are carried forward from the ongoing PFT evaluation, but added samples. A new data set which comprises ten print rolled images is included in the evaluation for PFTII. Details of the datasets are described in section 2.

With the increased size of the PFTII dataset, and three comparisons ( $p 2 p, p 2 r, r 2 r)$ for six fingers, the volume of image records has tripled. A new data storage management, "RecordStore", has been introduced and implemented in the PFTII evaluation process. Detail of the "RecordStore" will be described later in the evaluation strategy section.

Detection Error Trade-off (DET) curves, Equal error rate (EER), False Match Rate (FMR), and False non-Match Rate (FNMR) are shown in the report. There are several new measurements being reported for PFTII:

\footnotetext{
${ }^{1}$ SDK stands for Software Development Kit. Software libraries developed to a standardized application programming interface (API) are supplied to NIST for evaluation.

${ }^{2}$ ATB is a prototype evaluation system provided by the Federal Bureau of Investigation (FBI) to NIST to support benchmark studies of the Integrated Automated Fingerprint Identification System (IAFIS).
} 
- Fail To Enroll (FTE)

When the matcher fails to extract the template, a null template is created, and an FTE is counted. The null template will continue to be processed for the comparison which measures the true DET.

- Proprietary template size

The API has been modified to include the output of the size of proprietary template.

- Matcher's template enrollment time and comparison time

Both the enrollment and comparison time contain only CPU time (in micro seconds), deliberately omitting the $1 / O$ time.

- Confidence Interval for FMR and FNMR

$95 \%$ confidence intervals of $F N M R$ at $F M R=0.0001$, and FMR at FNMR $=\{0.002,0.005\}$ are computed by the binomial estimation with $\hat{p}-\delta \leq \hat{p} \leq \hat{p}+\delta$ were $\hat{p}$ is the computed FNMR and FMR,

$$
\delta=\Phi^{-1}(1-\alpha / 2) *(\hat{p}(1-\hat{p}) / \mathrm{N})^{1 / 2}
$$

$\mathrm{N}=$ the sample size, $\Phi^{-1}$ is the inverse of cumulative Normal distribution, and $\alpha=0.05$.

This is based on previous research in PFT results, which showed that there is no significant difference between binomial and bootstrap estimations [4] in this application.

\section{Dataset}

Two of the two-finger datasets, DHS2 and POEBVA, are carried forward from the original PFT evaluation, but with additional $60 \mathrm{~K}$ pairs respectively. A new ten print dataset is created from a combination of two different data sources, Arizona Department of Public Safety (AZDPS) and LA County Sheriff Department (LA) to form dataset AZLA. A random 120K subjects with mates were selected from the joint set of subjects with more than one ten print record, and $120 \mathrm{~K}$ nonmate subjects from the joint set of having only one ten print record were selected. The distribution of the sample set AZLA is about $60 \%$ from AZ and $40 \%$ from LA of subjects with mates, and $12 \%$ from $A Z$ and $88 \%$ from LA for the non-mates. Note that there are more subjects with multiple ten print records in $A Z(\approx 100 \mathrm{~K}$ of $376 \mathrm{~K})$, while more subject with only one ten print record from $L A(\approx 1.5 \mathrm{M}$ of $1.6 \mathrm{M})$ as indicated from dataset descriptions in section 2.1.

The mate data used in dataset AZLA are pre-evaluated and consolidated using the NIST ATB system and the examiner confirmation. The original $60 \mathrm{~K}$ mates from DHS2 and POEBVA were consolidated from the PFT evaluations, but the new $60 \mathrm{~K}$ additional mates will be consolidated as needed as the PFTII evaluation progresses.

$1 \mathrm{~K}$ samples from datasets; AZ, LA, DHS2, and POEBVA were selected having a specific fixed image size on which the template size and timings are measured:
- AZ:
Probe $-800 \times 800$ pixels,
Gallery $-800 \times 800$ pixels
- LA:
Probe $-400 \times 776$ pixels,
Gallery $-422 \times 1000$ pixels
- DHS2:
Probe $-368 \times 368$ pixels,
Gallery $-368 \times 368$ pixels
- POEBVA:
Probe $-368 \times 368$ pixels,
Gallery $-500 \times 500$ pixels 
Description of datasets DHS2 and POEBVA can be found in [2], while AZDPS, and LA are listed as following:

\section{AZDPS data (AZ)}

Description

Data from the Arizona Department of Public Safety.

Number of Subjects

$\approx 270 \mathrm{~K}$ with one record

$\approx 105 \mathrm{~K}$ with 2 or more records

Impression Type

Live-scan Rolled and Plain records per Subject

One or more records per subject.

Each record contains one 10-print card.

\section{Finger Positions Captured}

10 fingerprints taken from rolled impressions and 10 fingerprints taken from 2 plain thumbs and segmentation of 2 plain slap- 4 images on the same 10 print card

Capture Device(s)

NA

None

\section{Availability}

\section{Government use only}

\section{Data Preparation}

Segmentations of 2 plain slap-4 impressions were done by NIST $n f \mathrm{seg}^{3}$ program. Only the successful automatic segmentation results were used. If one of the four segmented impressions failed the NIST Fingerprint Quality (NFIQ) program, then the other three segmented impressions were excluded as well. Only a few impressions were excluded for this reason.

Data used in the evaluation were consolidated for subjects with mutilple records.

\footnotetext{
${ }^{3} \mathrm{nfseg}$, a fingerprint segmentation algorithm, is in the NIST Biometric Image Software (NBIS) distribution which can be found in http://www.nist.gov/itl/iad/ig/nbis.cfm.
} 


\section{LA Country Sheriff Department (LA)}

Description

Data from the Los Angeles County Sheriff Department

\begin{tabular}{|c|c|}
\hline $\begin{array}{l}\text { Number of Subjects } \\
\qquad 1.5 \text { Million with one record } \\
\approx 74 \mathrm{~K} \text { with } 2 \text { or more records }\end{array}$ & $\begin{array}{l}\text { records per Subject } \\
\text { One or more records per subject. } \\
\text { Each record contains one 10-print card. }\end{array}$ \\
\hline $\begin{array}{l}\text { Impression Type } \\
\text { Live-scan and Ink } \\
\text { Rolled and Plain }\end{array}$ & $\begin{array}{l}\text { Finger Positions Captured } \\
10 \text { fingerprints taken from rolled } \\
\text { impressions and } 10 \text { fingerprints taken from } \\
2 \text { plain thumbs and segmentation of } 2 \\
\text { plain slap- } 4 \text { images on the same } 10 \text {-print } \\
\text { card }\end{array}$ \\
\hline $\begin{array}{l}\text { Capture Device(s) } \\
\text { DBI } 1133 S \\
\text { CGT EP } 1680 \\
\text { CSI CLS1 }\end{array}$ & $\begin{array}{l}\text { Other Available Images } \\
\text { Palm print } \\
\text { Face } \\
\text { Scar Mark and Tattoo }\end{array}$ \\
\hline Government use o & \\
\hline
\end{tabular}

\section{Data Preparation}

Segmentations of 2 plain slap-4 impressions were done by NIST $n f s e g$ program. Only the successful automatic segmentation results were used. If one of the four segmented impressions failed the NFIQ program, then the other three segmented impressions were excluded as well. Only a few impressions were excluded for this reason.

Data used in the evaluation were consolidated for subjects with multiple records.

\footnotetext{
${ }^{4}$ Specific hardware and software products identified in this report do not imply recommendation or endorsement by NIST.
} 


\subsection{PFTII dataset Image Quality}

All the fingerprint impressions in DHS2 and POEBVA are live scan. For AZLA, the impression types are mixed live scan and rescan from ten print cards; this mix is $93 \%$ from live scan and $7 \%$ from ink, as determined by meta-data provided with dataset.

The performance of the fingerprint recognition technique and the template extraction algorithm relies on the quality of the fingerprint images. The overall quality summarization for the sample datasets of PFTII are calculated by the following recommended equations from $[4]^{5}$ :

\begin{tabular}{|l|l|}
\hline FMR & Equations for NFIQ summarization \\
\hline 0.0001 & $105.41-5.41 p_{1}-9.15 p_{2}-23.82 p_{3}-55.81 p_{4}-105.41 p_{5}$ \\
\hline 0.001 & $102.75-2.75 p_{1}-5.37 p_{2}-14.38 p_{3}-42.25 p_{4}-102.75 p_{5}$ \\
\hline 0.01 & $101.91-1.91 p_{1}-3.97 p_{2}-10.24 p_{3}-34.03 p_{4}-101.91 p_{5}$ \\
\hline
\end{tabular}

where $p_{i}$ is the proportion of the fingerprints with NFIQ of value $i=1 \ldots 5$, for PFTII datasets fingerprints. The resulting quality summary index is shown on Figure 1 for plain finger 02,07 (right and left index fingers):

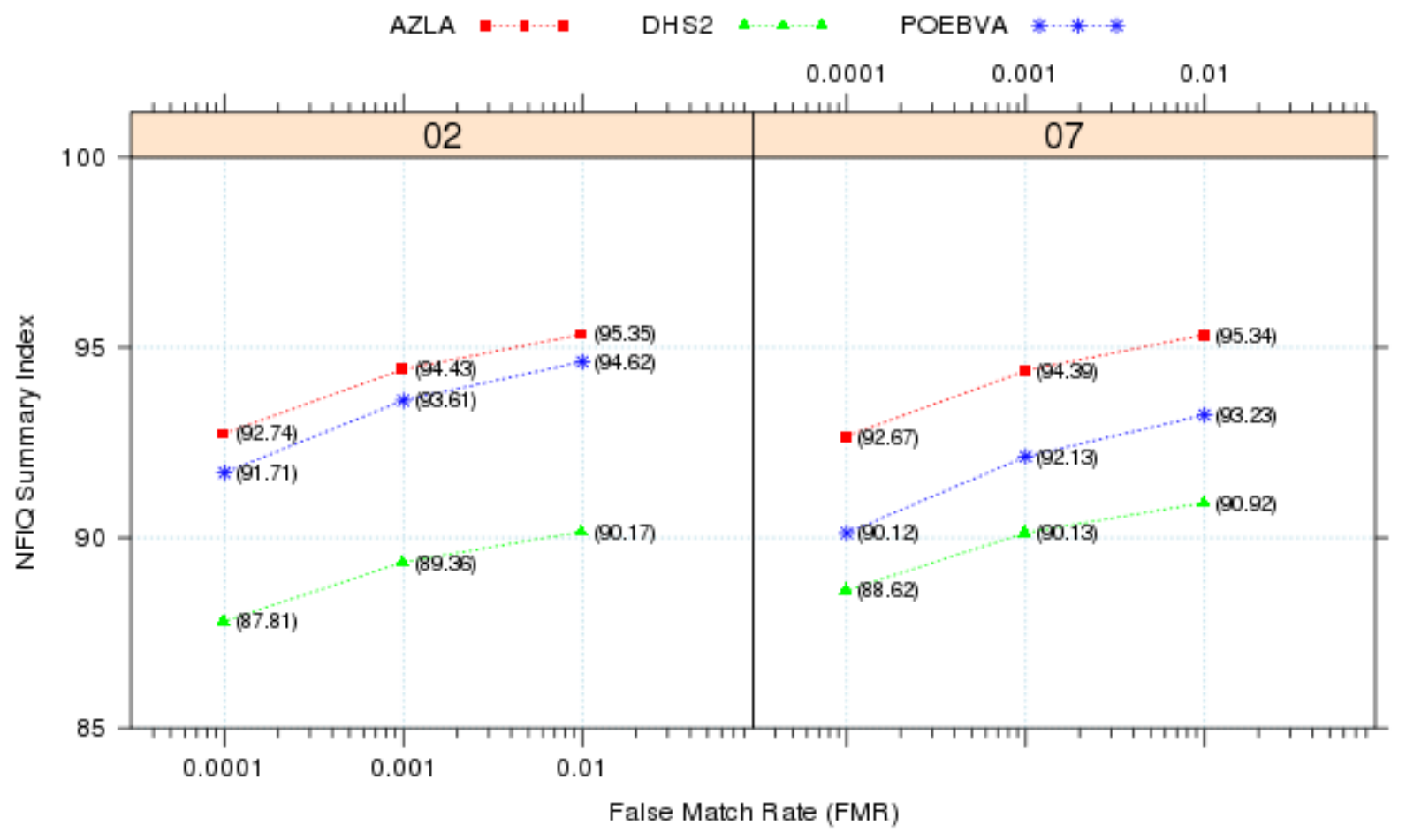

Figure 1: Dataset NIFQ Summaries

Figure 1 shows overall the quality indices of finger 02 and 07 for all three datasets: AZLA, POEBVA, and DHS2. The index is in the range of $[0,100]$ where 0 represents the lowest quality,

\footnotetext{
${ }^{5}$ This Biometric quality summarization is based on the weighted normalized NFIQ frequency for verification system.
} 
100 as the best quality, so the higher the summary index value, the better quality of the dataset. This is opposite the NFIQ index (the lower the better). Within each dataset, the quality differs. For ALZA, Finger 02 is slightly better than Finger 07. For DHS2, 07 is slightly better than 02. However in POEBVA, finger 02 is much better than 07 . In the summary section, we will analyze if there is any correlation of these quality indices with the matching performance of the algorithms.

\section{Evaluation Strategy}

PFTII continues to evaluate one-to-one fingerprint matching accuracy by the following configuration:

G : Gallery set of size 120,000 subjects

$\mathscr{P}_{\mathcal{M}} \quad$ : Probe mate set of size 120,000 subjects

$\mathscr{P}_{\mathcal{N} M} \quad$ : Probe non-mate of size 120,000 subjects

with the following constraints:

- $\mathscr{P}_{\mathcal{M}}$ contains exactly the same subject IDs as $\mathcal{G}$, but with images that have been acquired at a different time.

- Consolidation of Subject IDs

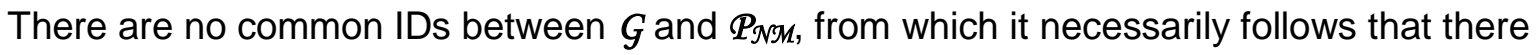

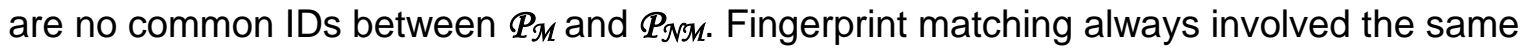
finger position only (e.g., right index to right index) for both the probes and the gallery.

The order of the matching of the pairs are computed randomly.

\subsection{RecordStore}

In PFTII, the total fingerprint images have more than tripled over that of PFT from 1.5 million to 5.8 million, while the number of comparisons jumped from 1.4 million to 5.2 million. This creates an extra load on the storage system with a much larger number of files to be processed.

Traditionally, the PFT evaluation would generate individual file output for each proprietary enrollment template from each participant, in addition to consuming large numbers of files as input. In many file systems, managing a huge number of files is not efficient and leads to difficulties for processing. The file system overhead ultimately hampers the runtime of the evaluation.

Therefore an alternative file I/O strategy was applied for PFTII. This strategy called, RecordStore, was designed by NIST to provide an abstraction for performing record-oriented input and output to an underlying storage system.

A RecordStore is an implementation of a data management strategy that is controlled by a common code interface to support basic methods such as read() and write(). One simple data management strategy is to store each record into a separate file, reproducing what has typically 
been done in the evaluation. Another strategy could be to store records in a remote relational database.

For PFTII, a Berkeley $\mathrm{DB}^{4}$ implementation of the RecordStore has been used, which provides significant speed improvements when reading and writing templates compared to individual files on disk. RecordStores maintain this flexibility in that they can be easily merged together into a larger RecordStore, a benefit which enables PFTII execution to be distributed across a cluster of blade computers while taking advantage of greatly improved $\mathrm{I} / \mathrm{O}$ throughput. This dramatically reduces the time of the entire evaluation process, making the large number of measurements feasible.

However the implementation of RecordStore does not affect the timing of enrollment nor the timing of the comparison since only the processing time is collected and measured.

\subsection{Hardware}

The $1 \mathrm{~K}$ sample evaluations are performed on a specific computer with $4 \mathrm{XAMD}^{4}$ Quad 2.3 $\mathrm{GHz} / 8 \mathrm{MB}$ cache processors, $192 \mathrm{~GB}$ of RAM, and a 64 bit operating system. The rest of the PFTII evaluations are ran from a list of available hardware as specified in the PFTII Evaluation Plan (http://www.nist.gov/itl/iad/ig/upload/PFTII_Evaluation_Plan.pdf).

\section{Results}

To simplify the notations in the report, finger positions are labeled according to the following:

\begin{tabular}{|c|c|c|c|c|c|c|c|c|c|}
\hline $\begin{array}{c}\text { Finger } \\
\text { position label }\end{array}$ & 01 & 02 & 03 & 06 & 07 & 08 & $01+06$ & $02+07$ & $03+08$ \\
\hline Description & $\begin{array}{c}\text { Right } \\
\text { Thumb }\end{array}$ & $\begin{array}{c}\text { Right } \\
\text { Index }\end{array}$ & $\begin{array}{c}\text { Right } \\
\text { Middle }\end{array}$ & $\begin{array}{c}\text { Left } \\
\text { Thumb }\end{array}$ & $\begin{array}{c}\text { Left } \\
\text { Index }\end{array}$ & $\begin{array}{c}\text { Left } \\
\text { Middle }\end{array}$ & $\begin{array}{c}\text { Right and } \\
\text { Left Thumb }\end{array}$ & $\begin{array}{c}\text { Right and } \\
\text { Left Index }\end{array}$ & $\begin{array}{c}\text { Right and } \\
\text { Left Middle }\end{array}$ \\
\hline
\end{tabular}

Table 1: Finger Position Description

Finger position 01, 02, and 03 are from the right hand, 06, 07, and 08 from the left hand, while $01+06,02+07$, and 03+08 represent the simple sum scores fusion from their respective finger positions.

To date, there have been three participants in PFTII listed as the following. The evaluation is ongoing and open to the entire fingerprint matching community (including vendors and academics).

\begin{tabular}{|c|l||}
\hline $\begin{array}{c}\text { Participant } \\
\text { code }\end{array}$ & Organization Name \\
\hline 3A & Avalon Biometrics S.L. \\
\hline 3B & ID Solutions, Inc. \\
\hline 3C & Patrima Technology Company \\
\hline
\end{tabular}

Table 2: PFTII Participant List as September 2011 
This report explicitly analyzes each matcher's algorithm, and illustrates: first the matcher's template size, enrollment timing, and comparison timing statistics; second, the performance by DET and error statistics for each individual matcher according to the different comparison types (p2p,p2r,r2r). Each matcher's results are categorized by the following two groups:

I. $1 \mathrm{~K}$ Sample Template Size and Timing statistics:

Figure $v^{*}-1$, Box chart and detail table for maximum, 75\%, median, 25\%, and Table $v-1$ minimum of template size.

Figure v-2, Box chart and detail table for maximum, $75 \%$, median, $25 \%$, and Table v-2 minimum time of enrollment and comparison in second.

II. Performance by DET curves and Error statistics:

Figure v-3 DET curves**: p2p comparison for datasets AZLA, DHS2, POEBVA, and all three combinations for finger 02, 07, 02+07.

Figure v-4 DET curves: p2p, p2r, and r2r for AZLA only, with fingers (01, 02 ,03, 06, 07, 08, 01+06, 02+07, 03+08)

Figure v-5, EERs and FTEs

Table v-3

Figure v-6, FMRs @ FNMR= $\{.002,0.005\}$ and 95\% Confidence Intervals Table $\mathrm{v}-4$

Figure v-7, FNMRs @ FMR =.0001 and 95\% Confidence Intervals Table $v-4$

Note: ${ }^{*} \mathrm{v}$ is substituted by $3 \mathrm{~A}, 3 \mathrm{~B}$, and $3 \mathrm{C}$.

** One set of curves which connects the FNMRs from a fixed matcher thresholds (scores are not normalized) which are corresponding to $F M R=\{0.0001,0.005,0.001,0.05$, $0.01\}$. For convenience, thresholds were selected from results of the POEBVA dataset and then applied to the DET curves for the other datasets.

The many figures and tables for each matcher are shown in Appendix A.

\subsection{Template Size}

Unlike the MINEX ${ }^{6}$ template format which has a size limit of 800 bytes with a standard fixed format, a proprietary template has no size limit with the matcher defined format.

The template size summary is displayed in Figure 2. There is a large variation in the resulting template size; the largest one from $3 \mathrm{~A}$ is four times the smallest one from $3 \mathrm{C}$ within each dataset. Even the smallest $3 \mathrm{C}$ sizes are larger than the maximum size of MINEX.

\footnotetext{
${ }^{6}$ MINEX is the NIST ongoing Minutiae Interoperability Exchange Test which uses International Committee for Information Technology Standards (INCITS) 378 specification.
} 
Detail of the five statistics distributions are shown in Figure and Table 3A-1, 3B-1, 3C -1 of Appendix A. We found that it's very consistent over matchers and datasets; the larger the image, the larger the proprietary template size.

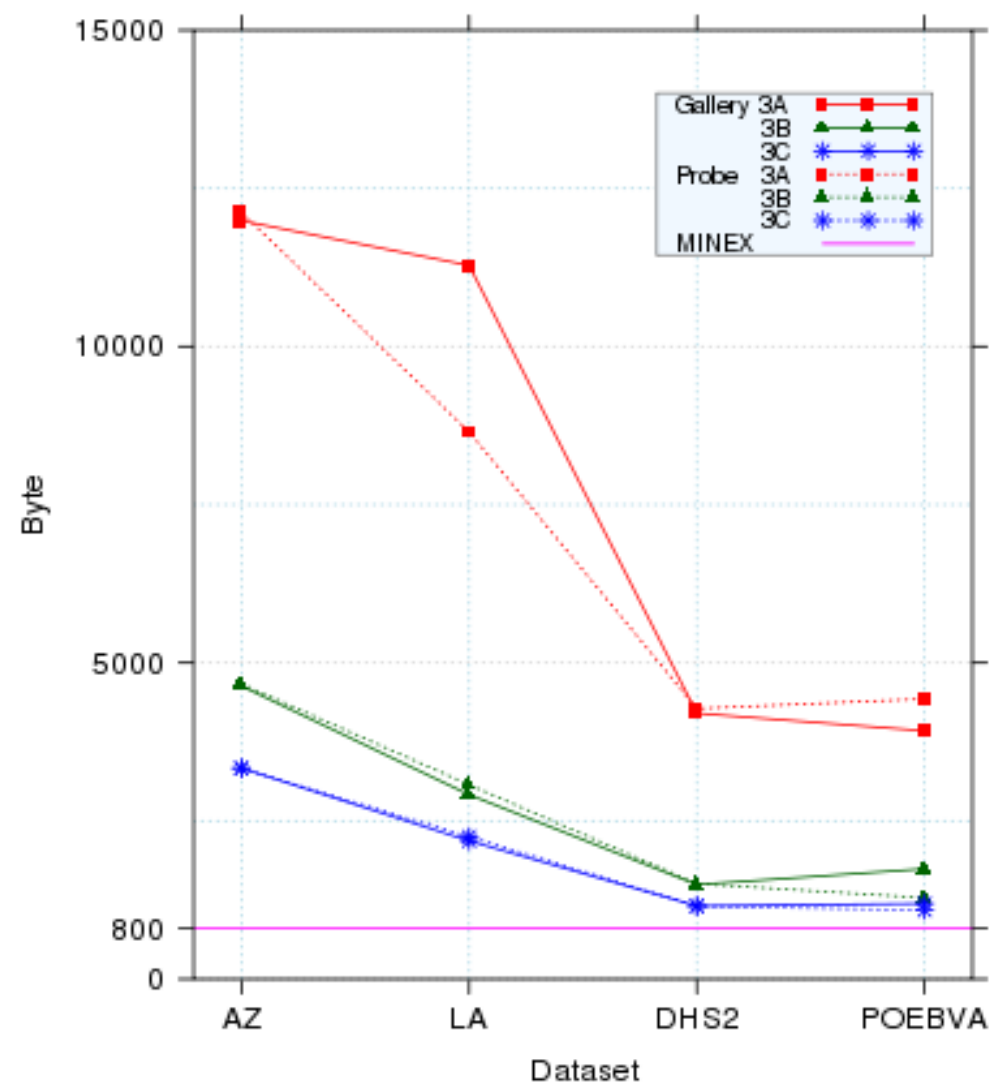

Figure 2: 1K Sample Template Size

\subsection{K Sample Enrollment and Comparison Timing}

As specified in the PFTII application evaluation plan (section 3.2), we recommend the average enrollment time not exceeding 3 second and comparison time not exceeding one tenth of a second. In Figure 3, the evaluation timing summary from the median of both timings, it is shown that all the matchers meet the recommendations in both enrollment and comparison. Figures 3A-2, 3B-2, and 3C-2 in Appendix A show the detailed timing statistics from each matcher by dataset. We make the following observations:

- The larger the template size is, the longer the time to enroll and to compare.

- The maximum enrollment time is $\approx 6$ seconds, while the minimum is $\approx 0$ seconds.

- With regard to possible relationship between the enrollment and comparison times, we observe (Figure 3), that one matcher has the longest median enrollment time (twice the shortest time) but has the shortest median comparison time (one tenth the longest time). The timings from the other two matchers are in similar ranges. 
- There is a big variation of the comparison time.

- A few of the maximum comparison times of the matchers are more than an order of magnitude greater than their own median time (Figure 3C-2 in Appendix A). This may be caused by the initialization from the matchers.

Enrollment Time (Median)

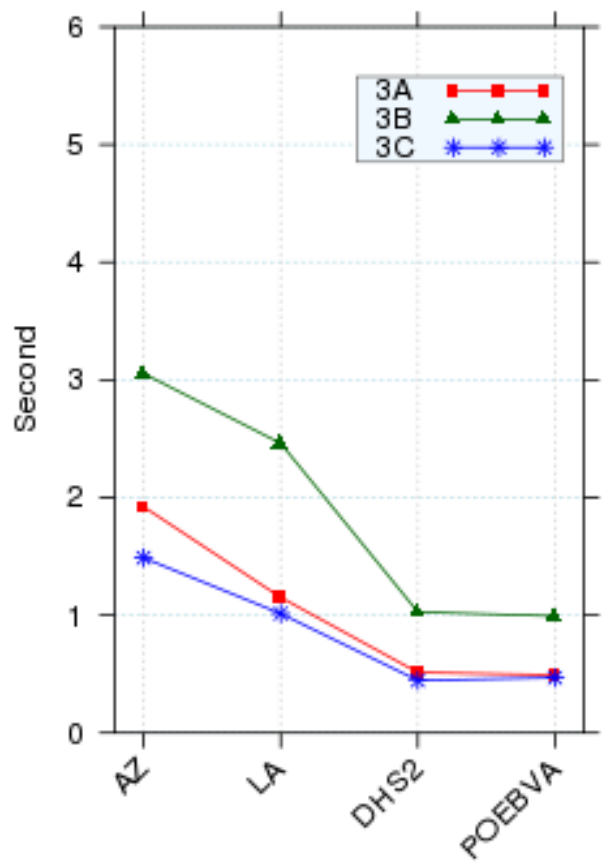

Dataset
Comparsion Time (Median)

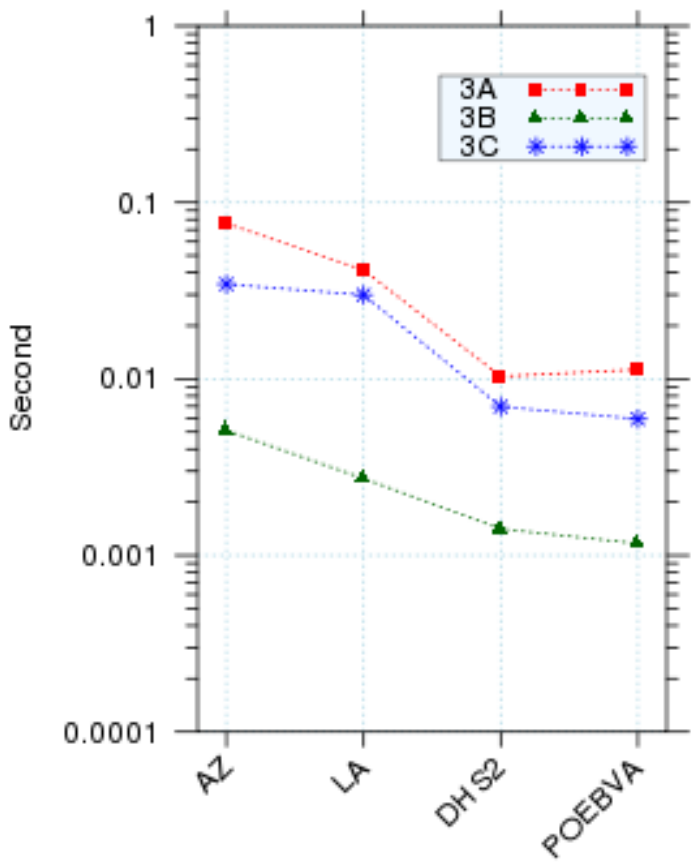

Dataset

Figure 3: 1K Sample Timing Summary

\subsection{Performance of P2P for Right Index, Left Index and two index fingers combined.}

DET characteristic curves from Figures 3A-3, 3B-3, and 3C-3 in Appendix A are one of the major performance measurements for the PFTII evaluation. The figures display the FNMRs in the range of $(0.0001 \leq F M R<0.1)$ of each matcher individually with respect to the different datasets: AZLA, DHS2, POEBVA and all three sets combined. Also in the figures, a list of FNMRs which are rendered through specific thresholds are obtained from the POEBVA dataset with $F M R=\{0.0001,0.0005,0.001,0.005\}$. This demonstrates the FNMRs from different datasets with the same thresholds. Note that the thresholds displayed are not normalized from the matcher scores.

Figure 4 is the summary of Figures 3A-3, 3B-3, and 3C-3 from Appendix A, by matcher. Figure 5 shows the summary of DETs by dataset. 


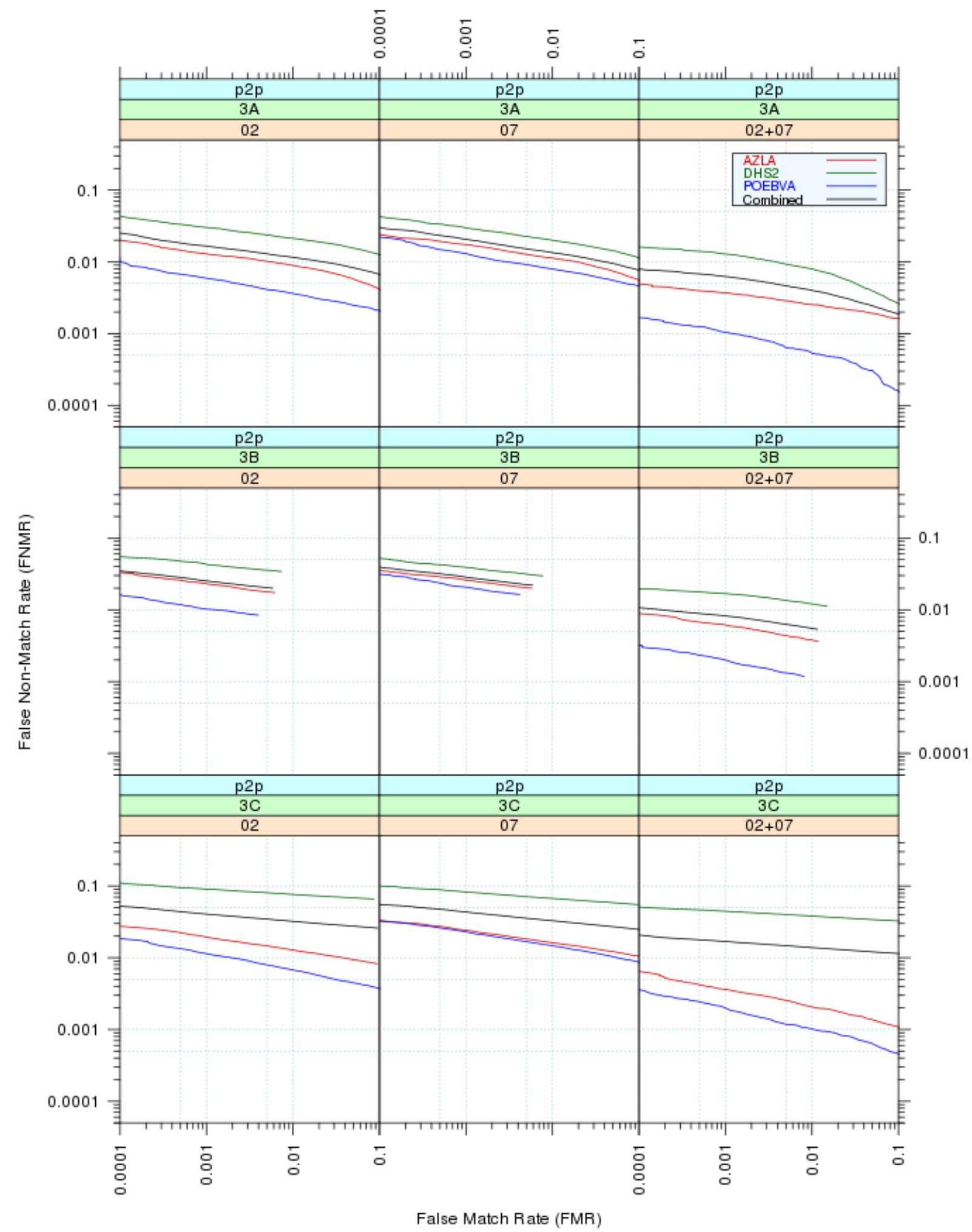

Figure 4: FNMR vs. FMR from matcher 3A, 3B, 3C for Plain vs. Plain Comparison by Right index, Left index, and two index fingers fusion.

3A $=$ Avalon Biometrics S.L. $\quad 3 B=$ ID Solutions, Inc. $\quad 3 C=$ Patrima Technology Company 


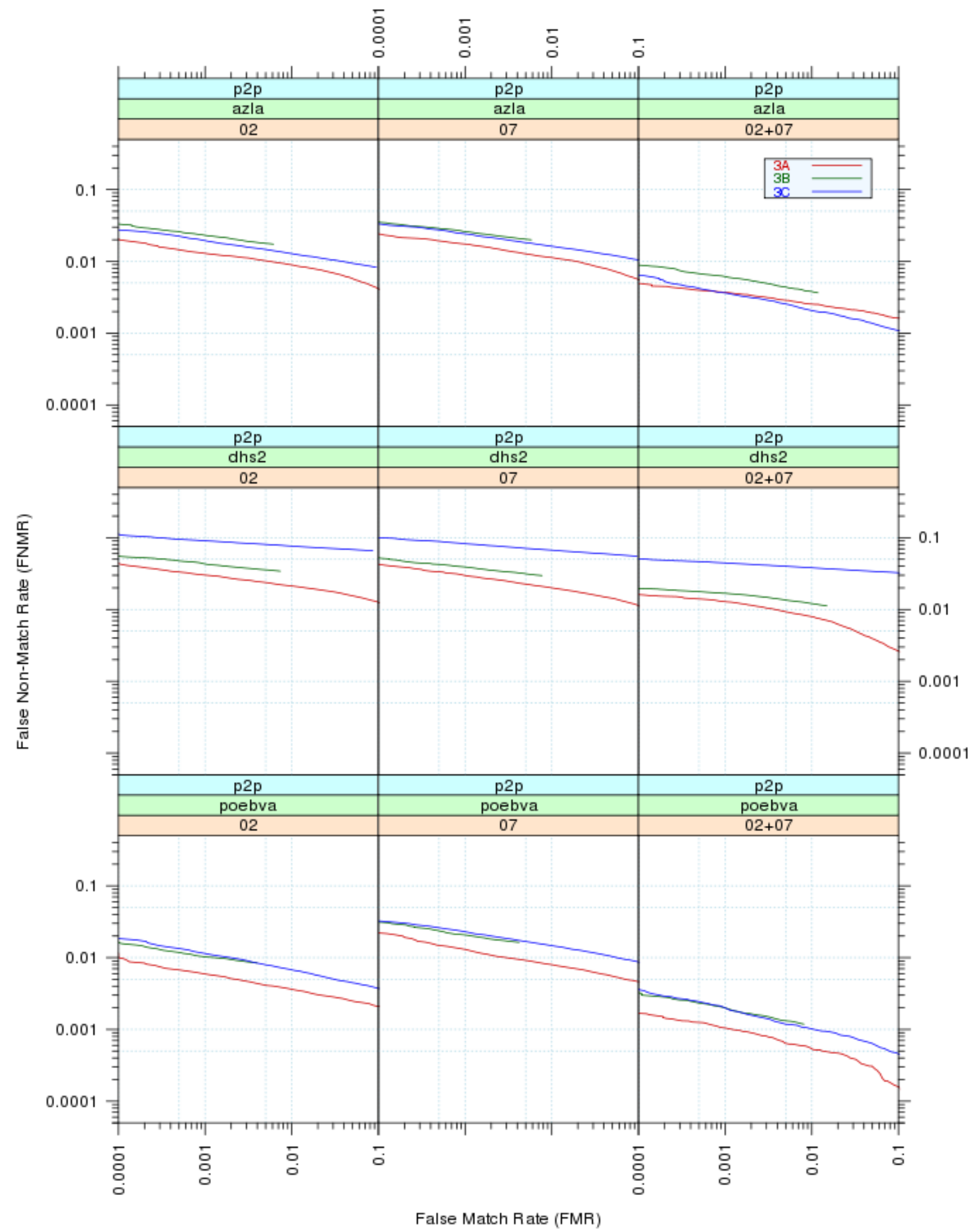

Figure 5: $\quad$ FNMR vs. FMR from AZLA, DHS2, POEBVA, for Plain vs. Plain Comparison by Right index, Left index, and two index fingers fusion. 
Together with Table 3 of the FNMRs at FMR $=\{0.0001,0.001\}$, and the observations, we find the following:

\begin{tabular}{|c|c|c|c|c|c|c|c|}
\hline \multicolumn{2}{|c|}{ Plain vs. Plain } & \multicolumn{7}{c|}{ FNMR } \\
\hline & & \multicolumn{3}{|c|}{ FMR $=0.0001$} & \multicolumn{3}{c|}{ FMR $=0.001$} \\
\hline Matcher & Finger & AZLA & DHS2 & POEBVA & AZLA & DHS2 & POEBVA \\
\hline 3A & 02 & 0.0199 & 0.0430 & 0.0099 & 0.0130 & 0.0301 & 0.0059 \\
\hline 3B & 02 & 0.0331 & 0.0554 & 0.0162 & 0.0234 & 0.0434 & 0.0102 \\
\hline 3C & 02 & 0.0273 & 0.1098 & 0.0185 & 0.0194 & 0.0904 & 0.0115 \\
\hline 3A & 07 & 0.0239 & 0.0418 & 0.0217 & 0.0174 & 0.0296 & 0.0130 \\
\hline 3B & 07 & 0.0350 & 0.0522 & 0.0318 & 0.0261 & 0.0393 & 0.0207 \\
\hline 3C & 07 & 0.0333 & 0.0993 & 0.0321 & 0.0242 & 0.0824 & 0.0228 \\
\hline 3A & $02+07$ & 0.0049 & 0.0160 & 0.0017 & 0.0037 & 0.0128 & 0.0011 \\
\hline 3B & $02+07$ & 0.0089 & 0.0196 & 0.0032 & 0.0063 & 0.0169 & 0.0020 \\
\hline 3C & $02+07$ & 0.0064 & 0.0507 & 0.0036 & 0.0036 & 0.0445 & 0.0020 \\
\hline
\end{tabular}

Table 3: FNMR values for Plain to Plain print comparison with right (02), left (07) index and the sum fusion $(02+07)$ from three datasets. Cells are shaded green with the lowest FNMR for each finger position among matchers.

- Regardless the matcher, dataset POEBVA continues to show the best results with the lowest FNMRs of the three sets, while DHS2 is the worst of the three sets; AZLA and all three datasets combined are second and third in the ranks. (Figure 4).

- However, according to the image quality summary index (Figure 1), AZLA is shown with better quality than POEBVA. One reason may be the plain index fingerprints were segmented from the slap image of the ten print card (which were rescaned from paper) for AZLA, while POEBVA plain index images were captured from live scan. DHS2 is the least accurate dataset which is consistent with the worst quality summary index.

- Right index finger (02) is more accurate than left index finger (07) except 3C, where there is no significant difference between them.

- There are no significant difference between 3B and $3 C$ for datasets POEBVA and AZLA (Figure 5 ), whereas there is a larger gap between $3 \mathrm{~B}$ and $3 \mathrm{C}$ from DHS2 where $3 \mathrm{~B}$ is close to $3 \mathrm{~A}$.

\subsection{Performance of Comparisons: Plain vs. Plain, Plain vs. Rolled, and Rolled vs. Rolled prints for Dataset AZLA.}

This is the second performance measurement for PFTII evaluation in Figure $\{3 A, 3 B, 3 C\}-4$ in Appendix A. In this section we study the performance differences among those three comparison types. In each of the individual matcher's DET figures, all three comparison types: p2p, p2r, and r2r, are displayed by six finger positions and three sum-fused results of the left and right positions. Regarding those figures, we make the following observations: 
- Again the simple two finger sum-fused are more accurate than single finger, regardless the finger positions $(01,02,03,06,07,08)$ and the comparison types.

- Right thumb (01), right index finger (02), and right middle finger (03) perform slightly better than those same positions from the left $(06,07,08)$ for matcher $3 \mathrm{~A}$, while there are no significant difference from matcher $3 \mathrm{~B}$ and $3 \mathrm{C}$.

- $\quad$ For matcher $3 \mathrm{~A}$ and $3 \mathrm{~B}, \mathrm{r} 2 \mathrm{r}$ has higher accuracy than $\mathrm{p} 2 \mathrm{p}$ or $\mathrm{p} 2 \mathrm{r}$ for index fingers (02, $07)$ and middle fingers $(03,08)$ as indicated in [3]. However, there is no significant differences for the $\mathrm{p} 2 \mathrm{p}$ and $\mathrm{p} 2 \mathrm{r}$ for the thumb positions $(01,06)$.

- For matcher 3C, all the p2p, p2r, and r2r are very similar, where $r 2 r$ is slightly better with all the fingers except the thumbs $(01,06)$ where $p 2 p$ is better than $p 2 r$ and $r 2 r$.

Besides the matcher individual figures in Appendix A, one summary table and three figures are included below.

- Table 4 shows the FNMR values for three comparison types, grouped by matcher and finger position.

- Figure 6, 7, and 8 display the FMR vs. FNMR for each comparison type.

The figures demonstrate the difference between the comparison types, or the similar results within the same type of comparison among the algorithms.

In order to be comparable to the previous PFT evaluations, an additional testing set is setup with a gallery subset of size $60 \mathrm{~K}$, a probe mate subset of size $60 \mathrm{~K}$, and the same probe nonmate set of size $120 \mathrm{~K}$ for the three datasets: AZLA, POEBVA, and DHS2 for fingers 02,07 and $02+07$. In this way, the DET and ROC curves are based on 60K genuine scores and $120 \mathrm{~K}$ imposter scores. These figures and tables are also included in Appendix B.

\subsection{FTE and EER}

Table 5 displays FTE counts for each algorithm. Theoretically, FTEs should contribute to higher error rate for FNMRs, nevertheless the rate is so small $(0 \leq \mathrm{FTE} \leq 0.0021)$ that it has shown little impact on the results from our observations. Noted that FTE $=0$ for matcher $3 \mathrm{~B}$ across all enrollments.

For $30 \%$ of matcher 3B's comparisons, EER could not be produced because the minimum of FNMR is greater than the maximum of FMR. 


\begin{tabular}{|c|c|c|c|c|c|c|c|}
\hline \multirow{2}{*}{$\begin{array}{c}\text { Comparison } \\
\text { Type }\end{array}$} & \multirow[t]{2}{*}{ Matcher } & \multicolumn{3}{|c|}{$\mathrm{FMR}=0.0001$} & \multicolumn{3}{|c|}{$\mathrm{FMR}=0.001$} \\
\hline & & 01 & 02 & 03 & 01 & 02 & 03 \\
\hline & $3 A$ & 0.0095 & 0.0199 & 0.0228 & 0.0062 & 0.0130 & 0.0172 \\
\hline & $3 \mathrm{~B}$ & 0.0098 & 0.0331 & 0.0299 & 0.0064 & 0.0234 & 0.0193 \\
\hline & $3 C$ & 0.0177 & 0.0273 & 0.0286 & 0.0132 & 0.0194 & 0.0219 \\
\hline & & 06 & 07 & 08 & 06 & 07 & 08 \\
\hline & $3 A$ & 0.0101 & 0.0239 & 0.0260 & 0.0072 & 0.0174 & 0.0196 \\
\hline & $3 B$ & 0.0071 & 0.0350 & 0.0285 & 0.0054 & 0.0261 & 0.0209 \\
\hline & $3 C$ & 0.0214 & 0.0333 & 0.0373 & 0.0153 & 0.0242 & 0.0280 \\
\hline & & $01+06$ & $02+07$ & $03+08$ & $01+06$ & $02+07$ & $03+08$ \\
\hline & $3 A$ & 0.0021 & 0.0049 & 0.0070 & 0.0016 & 0.0037 & 0.0055 \\
\hline & $3 \mathrm{~B}$ & 0.0019 & 0.0089 & 0.0091 & 0.0014 & 0.0063 & 0.0065 \\
\hline & $3 C$ & 0.0041 & 0.0064 & 0.0093 & 0.0027 & 0.0036 & 0.0063 \\
\hline \multirow[t]{12}{*}{ Plain vs. Rolled } & & 01 & 02 & 03 & 01 & 02 & 03 \\
\hline & $3 A$ & 0.0123 & 0.0194 & 0.0242 & 0.0080 & 0.0140 & 0.0175 \\
\hline & $3 \mathrm{~B}$ & 0.0095 & 0.0300 & 0.0229 & 0.0076 & 0.0197 & 0.0166 \\
\hline & $3 C$ & 0.0278 & 0.0402 & 0.0434 & 0.0202 & 0.0287 & 0.0316 \\
\hline & & 06 & 07 & 08 & 06 & 07 & 08 \\
\hline & $3 A$ & 0.0153 & 0.0252 & 0.0255 & 0.0098 & 0.0173 & 0.0193 \\
\hline & $3 \mathrm{~B}$ & 0.0086 & 0.0293 & 0.0234 & 0.0065 & 0.0217 & 0.0179 \\
\hline & $3 C$ & 0.0362 & 0.0424 & 0.0508 & 0.0259 & 0.0329 & 0.0379 \\
\hline & & $01+06$ & $02+07$ & $03+08$ & $01+06$ & $02+07$ & $03+08$ \\
\hline & $3 A$ & $\begin{array}{l}0.0027 \\
\end{array}$ & 0.0056 & 0.0072 & 0.0024 & 0.0037 & 0.0051 \\
\hline & $3 B$ & 0.0023 & 0.0085 & 0.0074 & 0.0018 & 0.0057 & 0.0055 \\
\hline & $3 C$ & 0.0080 & 0.0110 & 0.0151 & 0.0053 & 0.0065 & 0.0092 \\
\hline \multirow[t]{12}{*}{$\begin{array}{c}\text { Rolled vs. } \\
\text { Rolled }\end{array}$} & & 01 & 02 & 03 & 01 & 02 & 03 \\
\hline & $3 A$ & 0.0091 & 0.0070 & 0.0084 & 0.0076 & 0.0047 & 0.0060 \\
\hline & $3 \mathrm{~B}$ & 0.0057 & 0.0066 & 0.0054 & 0.0046 & 0.0051 & 0.0046 \\
\hline & $3 \mathrm{C}$ & 0.0301 & 0.0266 & 0.0260 & 0.0222 & 0.0197 & 0.0190 \\
\hline & & 06 & 07 & 08 & 06 & 07 & 08 \\
\hline & $3 A$ & 0.0123 & 0.0083 & 0.0109 & 0.0077 & 0.0052 & 0.0071 \\
\hline & $3 \mathrm{~B}$ & 0.0046 & 0.0072 & 0.0062 & 0.0039 & 0.0057 & 0.0052 \\
\hline & $3 C$ & \begin{tabular}{|l}
0.0383 \\
\end{tabular} & $\begin{array}{l}0.0317 \\
\end{array}$ & \begin{tabular}{|l|}
0.0299 \\
\end{tabular} & \begin{tabular}{|l}
0.0267 \\
\end{tabular} & \begin{tabular}{|l}
0.0208 \\
\end{tabular} & \begin{tabular}{|l}
0.0217 \\
\end{tabular} \\
\hline & & $01+06$ & $02+07$ & $03+08$ & $01+06$ & $02+07$ & $03+08$ \\
\hline & $3 A$ & 0.0023 & 0.0014 & 0.0018 & 0.0023 & 0.0014 & 0.0018 \\
\hline & $3 B$ & 0.0013 & 0.0017 & 0.0015 & 0.0009 & 0.0012 & 0.0013 \\
\hline & $3 C$ & 0.0104 & 0.0079 & 0.0088 & 0.0072 & 0.0055 & 0.0063 \\
\hline
\end{tabular}

Table 4: $\quad F N M R$ values for Dataset AZLA at FMR $=\{0.0001,0.001\}$ with all finger positions and all three comparison types. 


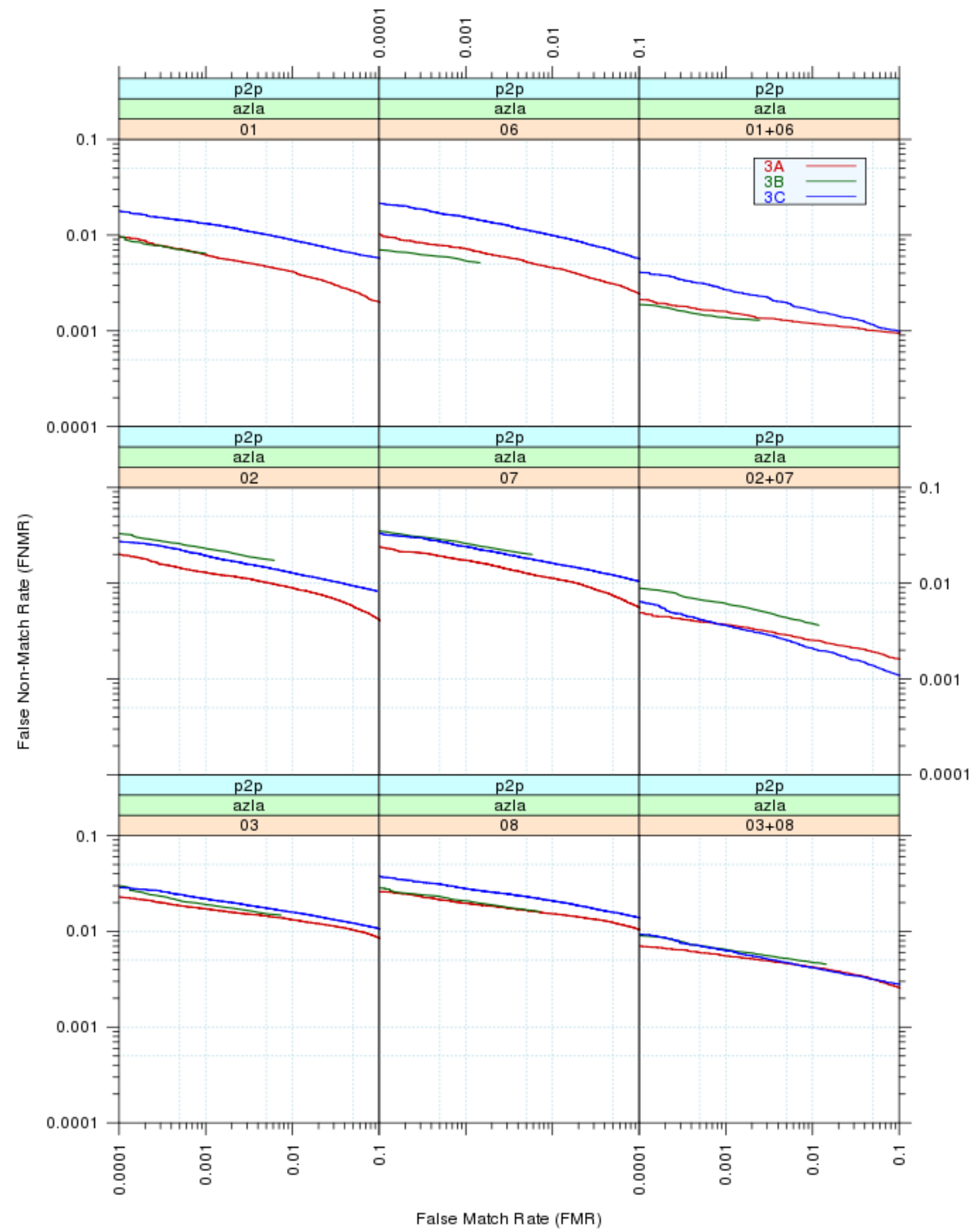

Figure 6: FNMR vs. FMR from AZLA for Plain vs. Plain with all finger positions and their respective sum fusions. 


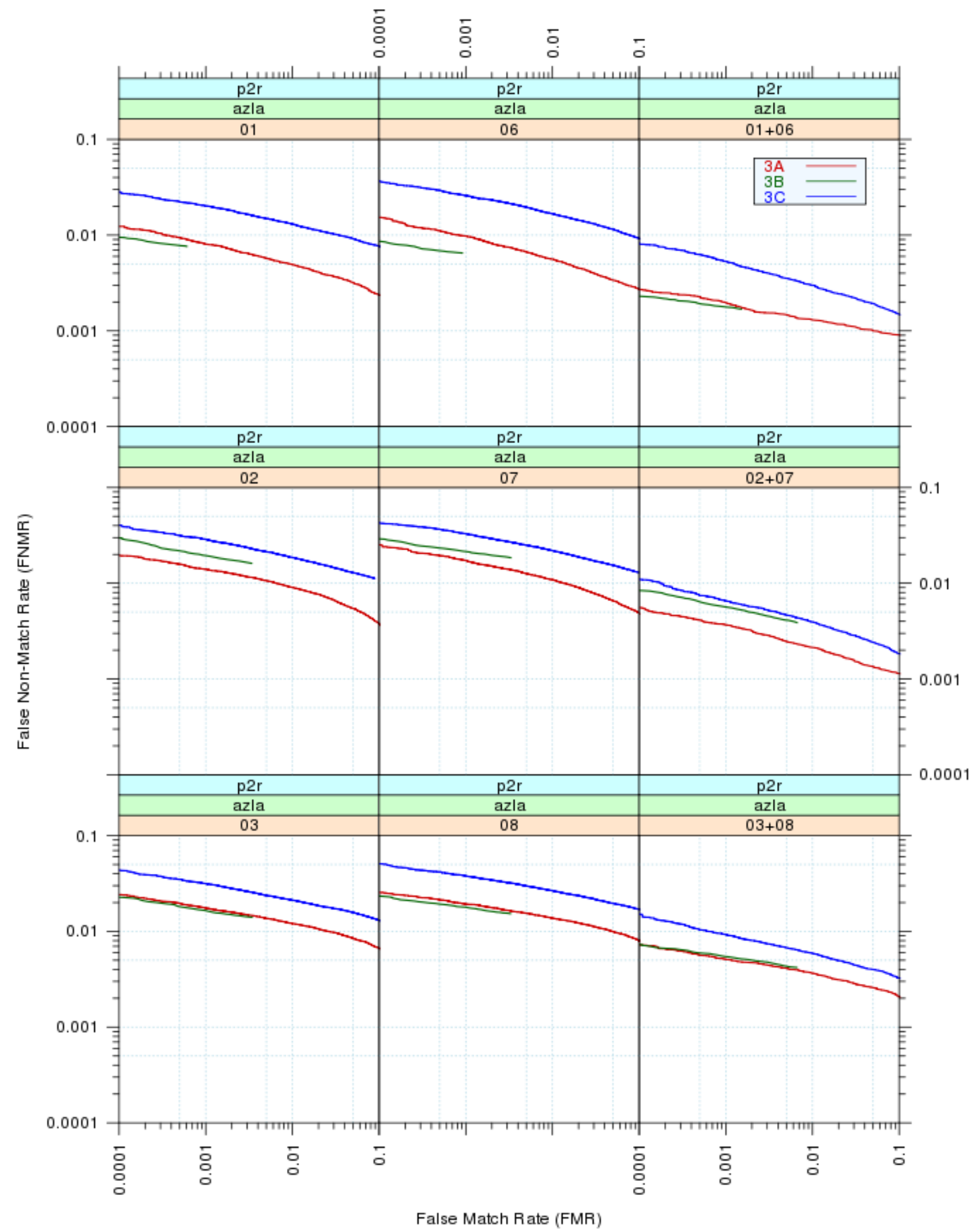

Figure 7: FNMR vs. FMR from AZLA for Plain vs. rolled with all finger positions and their respective sum fusions. 


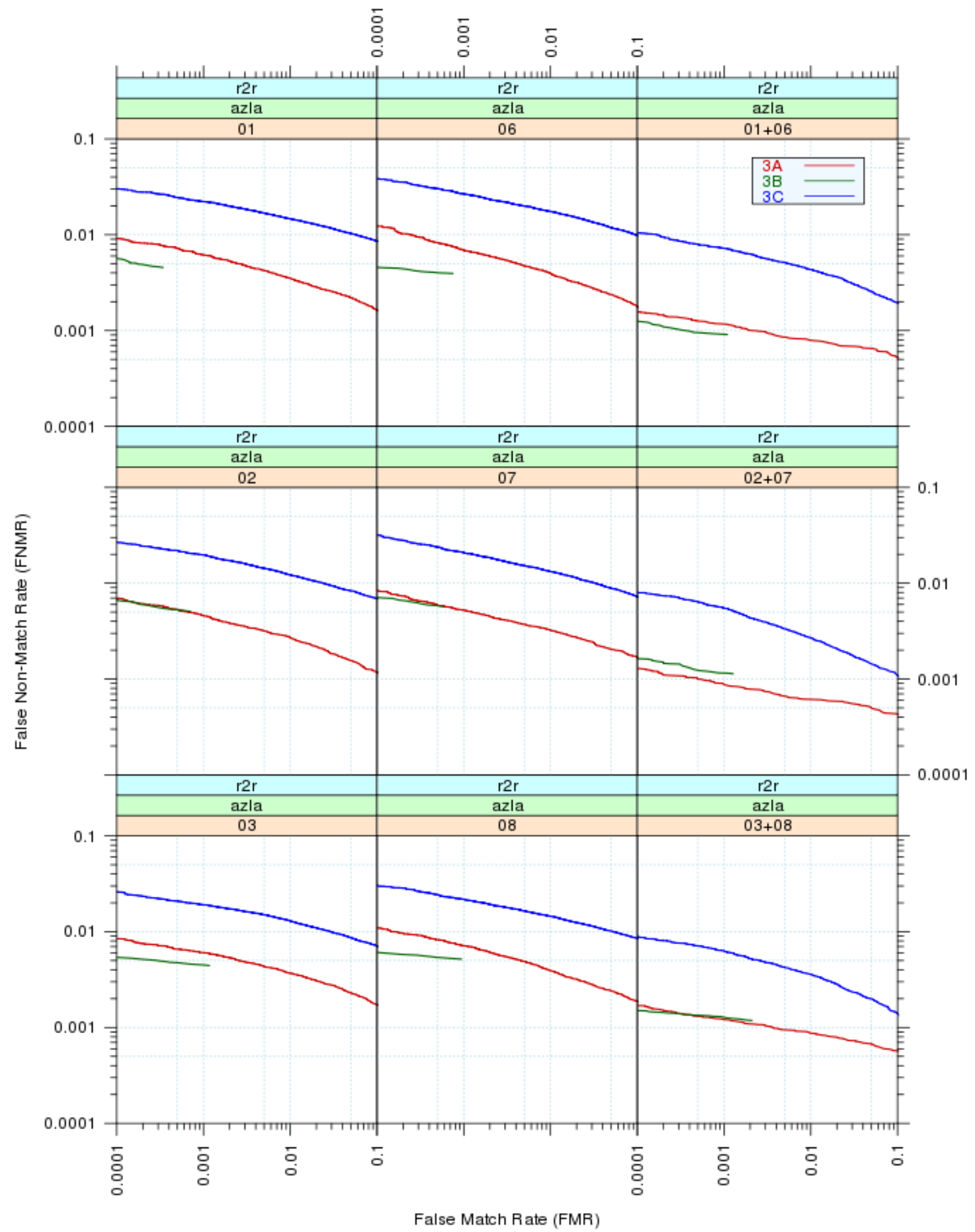

Figure 8: FNMR vs. FMR from AZLA for Plain vs. Plain with all finger positions and their respective sum fusions. 


\begin{tabular}{|c|c|c|c|c|c|}
\hline \multirow{2}{*}{$\begin{array}{c}\text { Comparison } \\
\text { Type }\end{array}$} & \multirow{2}{*}{ Dataset } & \multirow{2}{*}{$\begin{array}{l}\text { Finger } \\
\text { Position }\end{array}$} & \multicolumn{3}{|c|}{ FTE Count } \\
\hline & & & $3 A$ & $3 \mathrm{~B}$ & $3 C$ \\
\hline \multirow[t]{9}{*}{ p2p } & AZLA & 02 & 69 & 5 & 0 \\
\hline & & 07 & 81 & 2 & 0 \\
\hline & & $02+07$ & 150 & 7 & 0 \\
\hline & DHS2 & 02 & 45 & 762 & 0 \\
\hline & & 07 & 31 & 524 & 0 \\
\hline & & $02+07$ & 76 & 1286 & 0 \\
\hline & POEBVA & 02 & 1 & 0 & 0 \\
\hline & & 07 & 0 & 0 & 0 \\
\hline & & $02+07$ & 1 & 0 & 0 \\
\hline \multirow{9}{*}{ p2p } & AZIA & 01 & 37 & 40 & 0 \\
\hline & & 02 & 69 & 5 & 0 \\
\hline & & 03 & 25 & 0 & 0 \\
\hline & & 06 & 24 & 26 & 0 \\
\hline & & 07 & 81 & 2 & 0 \\
\hline & & 08 & 17 & 4 & 0 \\
\hline & & $01+06$ & 61 & 66 & 0 \\
\hline & & $02+07$ & 150 & 7 & 0 \\
\hline & & $03+08$ & 42 & 4 & 0 \\
\hline \multirow{9}{*}{$p 2 r$} & A7|A & 01 & 26 & 35 & 0 \\
\hline & & 02 & 28 & 9 & 0 \\
\hline & & 03 & 14 & 5 & 0 \\
\hline & & 06 & 17 & 16 & 0 \\
\hline & & 07 & 33 & 7 & 0 \\
\hline & & 08 & 17 & 9 & 0 \\
\hline & & $01+06$ & 43 & 51 & 0 \\
\hline & & $02+07$ & 61 & 16 & 0 \\
\hline & & $03+08$ & 31 & 14 & 0 \\
\hline \multirow{9}{*}{$r 2 r$} & A그 & 01 & 16 & 26 & 0 \\
\hline & & 02 & 9 & 13 & 0 \\
\hline & & 03 & 6 & 11 & 0 \\
\hline & & 06 & 9 & 11 & 0 \\
\hline & & 07 & 6 & 7 & 0 \\
\hline & & 08 & 13 & 14 & 0 \\
\hline & & $01+06$ & 25 & 37 & 0 \\
\hline & & $02+07$ & 15 & 20 & 0 \\
\hline & & $03+08$ & 19 & 25 & 0 \\
\hline
\end{tabular}

Table 5: FTE Counts for all matchers, and the total number for a single finger is 360,000 , and the total two fingers sum fusion is 720,000 . 


\section{Summary}

From the results on three SDK matchers, each algorithm demonstrates different performance by the three comparison types. We have found there are some uncertainties and some similarities as follows:

- The simple two fingers sum-fused score results is better than one single finger.

- All the algorithms performed the best with dataset POEBVA.

- The majority of rolled vs. rolled results are better than plain .vs. plain or plain vs. rolled, except 3C (Figure 3C-4 in Appendix A).

- Thumb comparison is not always better than index finger or middle finger. E.g., thumb comparison for $3 \mathrm{~A}$ is worse with rolled vs. rolled (Figure 3A-4 in Appendix A).

PFTII is an on-going NIST evaluation program. Future SDK matcher results will be published to the PFTII web site at http://www.nist.gov/it//iad/ig/pttii_results.cfm. A future report is planned to evaluate previous PFT and MINEX results to study the improvement in fingerprint matching performance over time.

\section{References}

[1] Craig I. Watson, Charles Wilson, Mike Indovina, Brian Cochran: "Two Finger matching with Vendor SDK Matchers"; NISTIR 7249, July 2005.

[2] C. I. Watson, C. L. Wilson, K. Marshall, R. Snelick, "Studies of One-to-One Fingerprint matchers with Vendor SDK matchers”; NISTIR 7221, April 2005.

[3] Stephen S. Wood and Charles L. Wilson; "Studies of Plain-to-Rolled Fingerprint Matching Using the NIST Algorithmic Test Bed (ATB)"; NISTIR 7112; April, 2004.

[4] Elham Tabassi, Patrick Grother, "Quality Summarization Recommendations on Biometric Quality Summarization across the Application Domain"; NISTIR 7422,May,2007.

[5] Su Lan Cheng, Ross Micheals, Z.Q. John Lu;" Comparison of Confidence Intervals for Large Operational Biometric Data by Parametric and Non-parametric Methods"; NISTIR 7740, November, 2010. 


\section{Appendix - A}

Table of Content

\begin{tabular}{|c|c|c|}
\hline Page & Figure/Table & Description \\
\hline A-2 & Figure $3 A-1 \&$ Table $3 A-1$ & 1K Sample Template Size Distribution \\
\hline A-3 & Figure 3A-2 \& Table 3A-2 & 1K Sample Enrollment and Comparison Timing Statistics \\
\hline A-4 & Figure $3 \mathrm{~A}-3$ & $\begin{array}{l}\text { DET for POEBVA, DHS2, AZLA, and all three combined } \\
\text { from finger } 02,07 \text {, and } 02+07^{*}\end{array}$ \\
\hline A-5 & Figure 3A-4 & $\begin{array}{l}\text { DET for all Finger Positions; }(01,02,03,06,07,08,01+06 \text {, } \\
02+07,03+08)^{\star} \text { from AZLA }\end{array}$ \\
\hline A-6 & Figure $3 A-5$ & EERs and FTEs \\
\hline$A-7$ & Figure $3 A-6$ & $\begin{array}{l}\text { FMRs @ FNMR }=(.002,0.005) \text { and } 95 \% \text { Confidence } \\
\text { Intervals }\end{array}$ \\
\hline A-8 & Figure 3A-7 & FNMRs@ @ FMR =.0001 and 95\% Confidence Intervals \\
\hline A-9 & Table 3A-3 & Table Details for EERs and FTEs \\
\hline$A-10$ & Table 3A-4 & $\begin{array}{l}\text { Table Details for FNMRs @ FMR }=.0001, \text { and } \\
\text { FMRs @ FNMR }=(.002,0.005)\end{array}$ \\
\hline $\begin{array}{l}\text { A-11 to } \\
\text { A-20 }\end{array}$ & Figure 3B-1 to Table 3B-4 & Same from all the above descriptions \\
\hline $\begin{array}{l}\text { A-21 to } \\
\text { A-29 }\end{array}$ & Figure $3 \mathrm{C}-1$ to Table $3 \mathrm{C}-4$ & Same from all the above descriptions \\
\hline
\end{tabular}




\section{Matcher 3A}

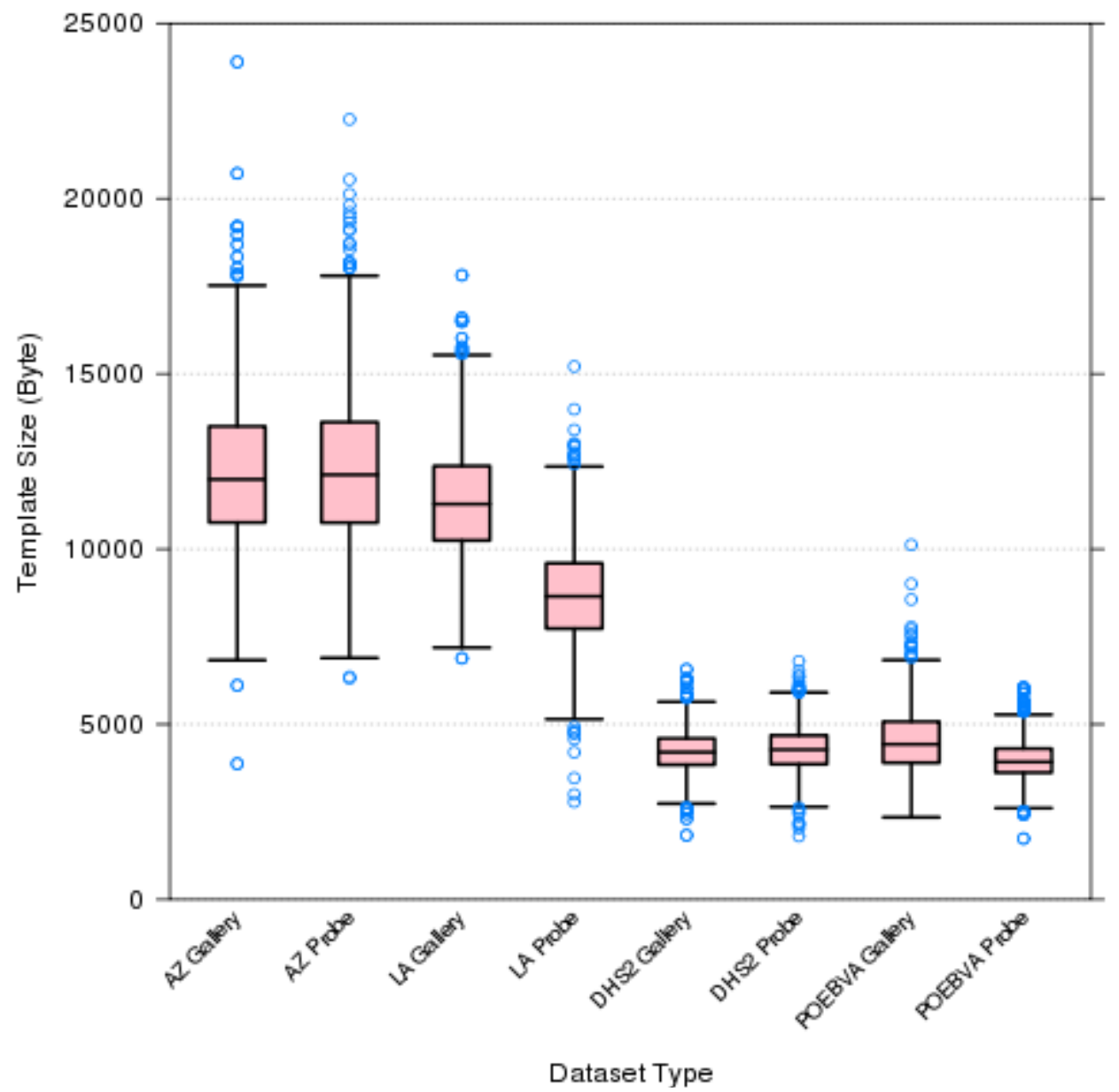

Figure 3A-1: 1K Sample Template Size Distribution

\begin{tabular}{|c|c|c|c|c|c|c|c|c|}
\hline Dataset & AZ & AZ & LA & LA & DHS2 & DHS2 & POEBVA & POEBVA \\
\hline Type & Gallery & Probe & Gallery & Probe & Gallery & Probe & Gallery & Probe \\
\hline $\begin{array}{c}\text { WidthxHeight } \\
\text { (pixels) }\end{array}$ & $800 \times 800$ & $800 \times 800$ & $412 \times 1000$ & $400 \times 776$ & $368 \times 368$ & $368 \times 368$ & $500 \times 500$ & $368 \times 368$ \\
\hline & & & & & & & & \\
\hline Maximum & 23901 & 22262 & 17814 & 15211 & 6566 & 6796 & 10120 & 6050 \\
\hline $75 \%$ & 13501 & 13622 & 12371 & 9595 & 4594 & 4683 & 5076 & 4307 \\
\hline Median & 11988 & 12121 & 11283 & 8651 & 4201 & 4275 & 4429 & 3924 \\
\hline $25 \%$ & 10758 & 10752 & 10246 & 7730 & 3842 & 3862 & 3901 & 3619 \\
\hline Minimum & 3875 & 6308 & 6883 & 2788 & 1834 & 1808 & 2346 & 1738 \\
\hline
\end{tabular}

Table 3A-1: Template Size (Byte) 

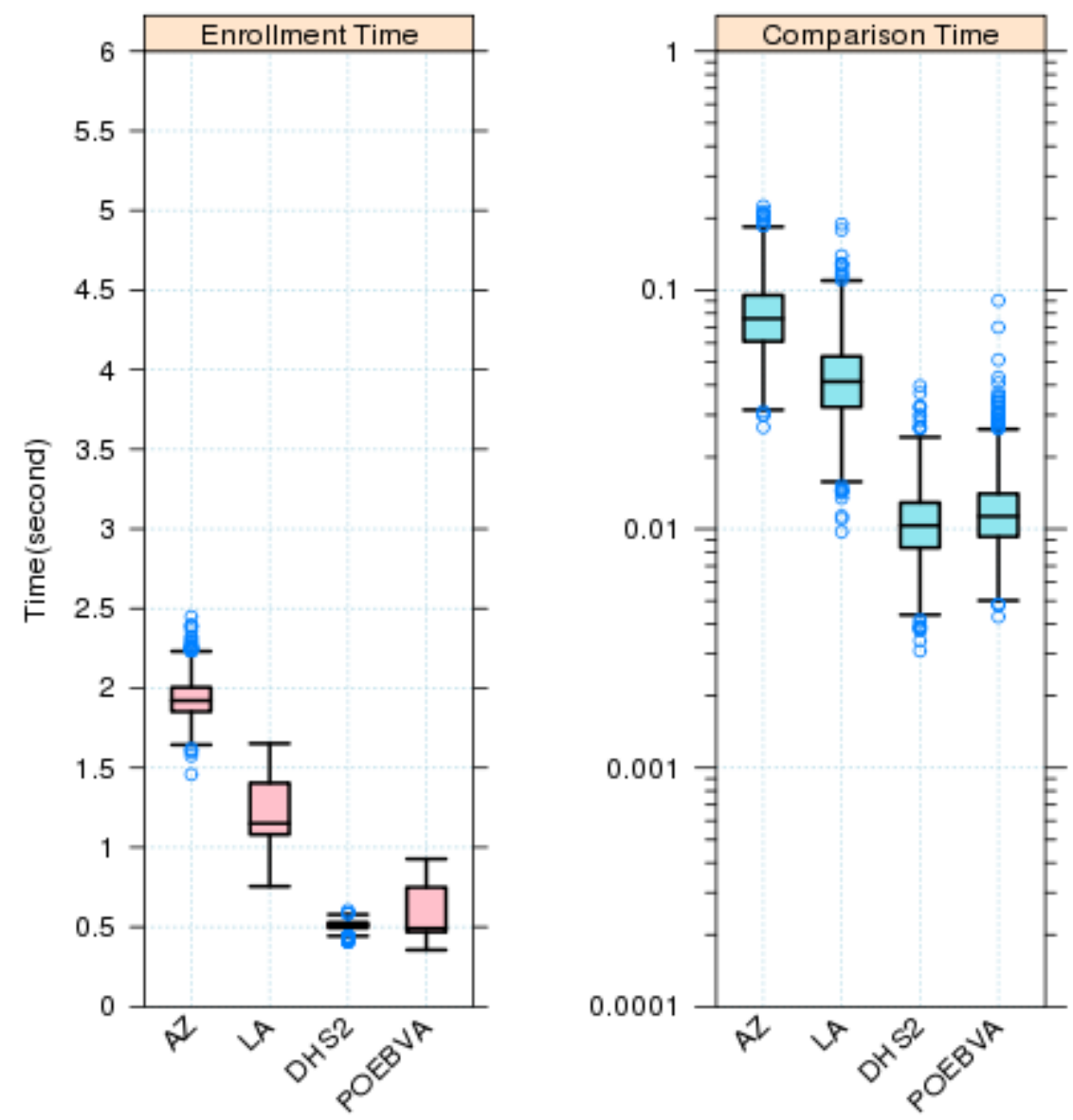

Figure 3A-2: 1K Sample Enrollment and Comparison Time

Enrollment Time (second)

\begin{tabular}{|c|c|c|c|c|}
\hline Dataset & AZ & LA & DHS2 & POEBVA \\
\hline & & & & \\
\hline Maximum & 2.4488 & 1.6522 & 0.6042 & 0.9276 \\
\hline $75 \%$ & 2.0047 & 1.4039 & 0.5283 & 0.7493 \\
\hline Median & 1.9216 & 1.1506 & 0.5124 & 0.4918 \\
\hline $25 \%$ & 1.8523 & 1.0811 & 0.4942 & 0.4694 \\
\hline Minimum & 1.4591 & 0.7552 & 0.4046 & 0.3557 \\
\hline
\end{tabular}

Comparison Time (second)

\begin{tabular}{|c|c|c|c|c|}
\hline Dataset & AZ & LA & DHS2 & POEBVA \\
\hline & & & & \\
\hline Maximum & 0.2245 & 0.1888 & 0.0397 & 0.0904 \\
\hline $75 \%$ & 0.0952 & 0.0527 & 0.0129 & 0.0140 \\
\hline Median & 0.0759 & 0.0414 & 0.0103 & 0.0113 \\
\hline $25 \%$ & 0.0609 & 0.0324 & 0.0083 & 0.0093 \\
\hline Minimum & 0.0267 & 0.0097 & 0.0031 & 0.0043 \\
\hline
\end{tabular}

Table 3A-2: Enrollment and Comparison Time (second) 


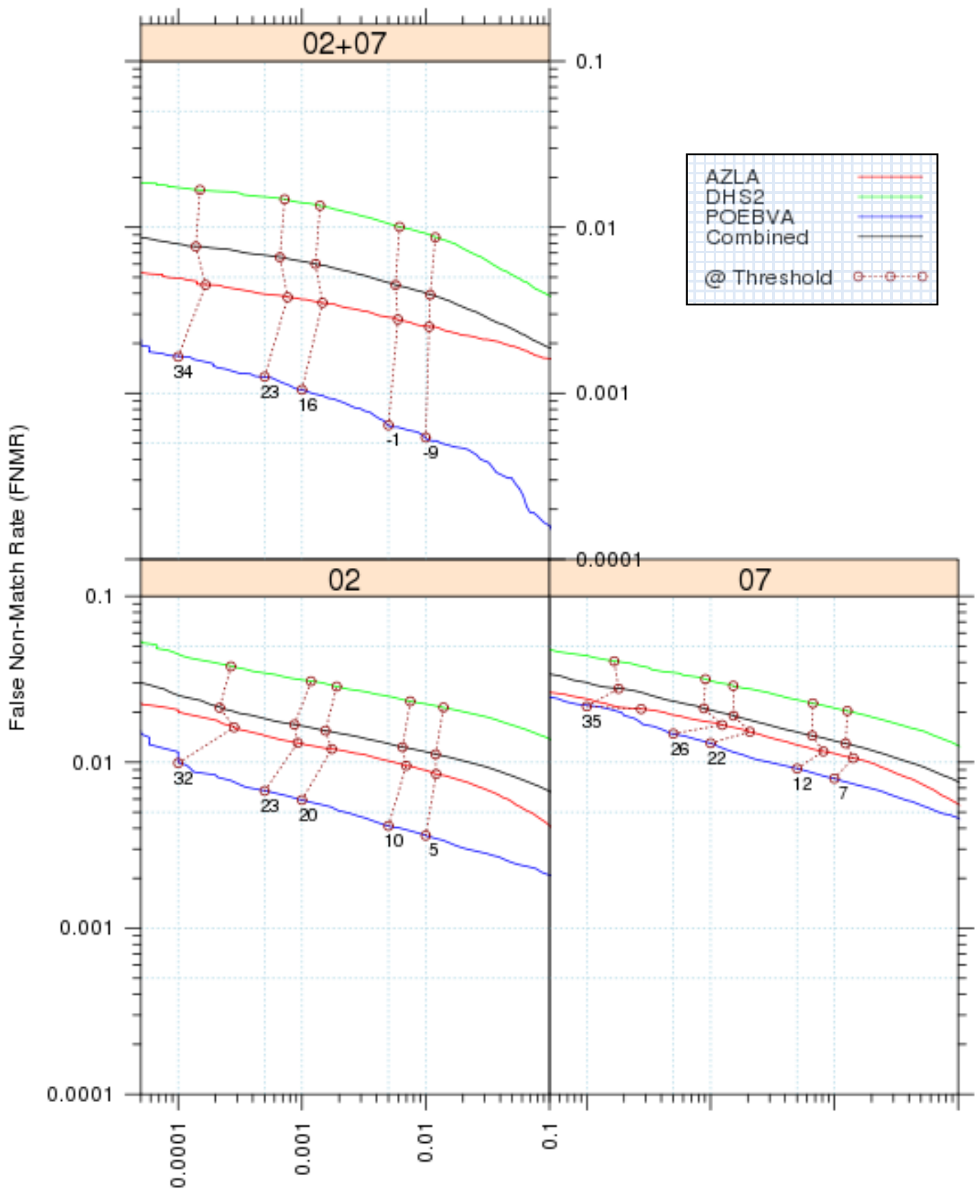

False Match Rate (FMR)

Figure 3A-3: DET for ALL Datasets (P2P) 


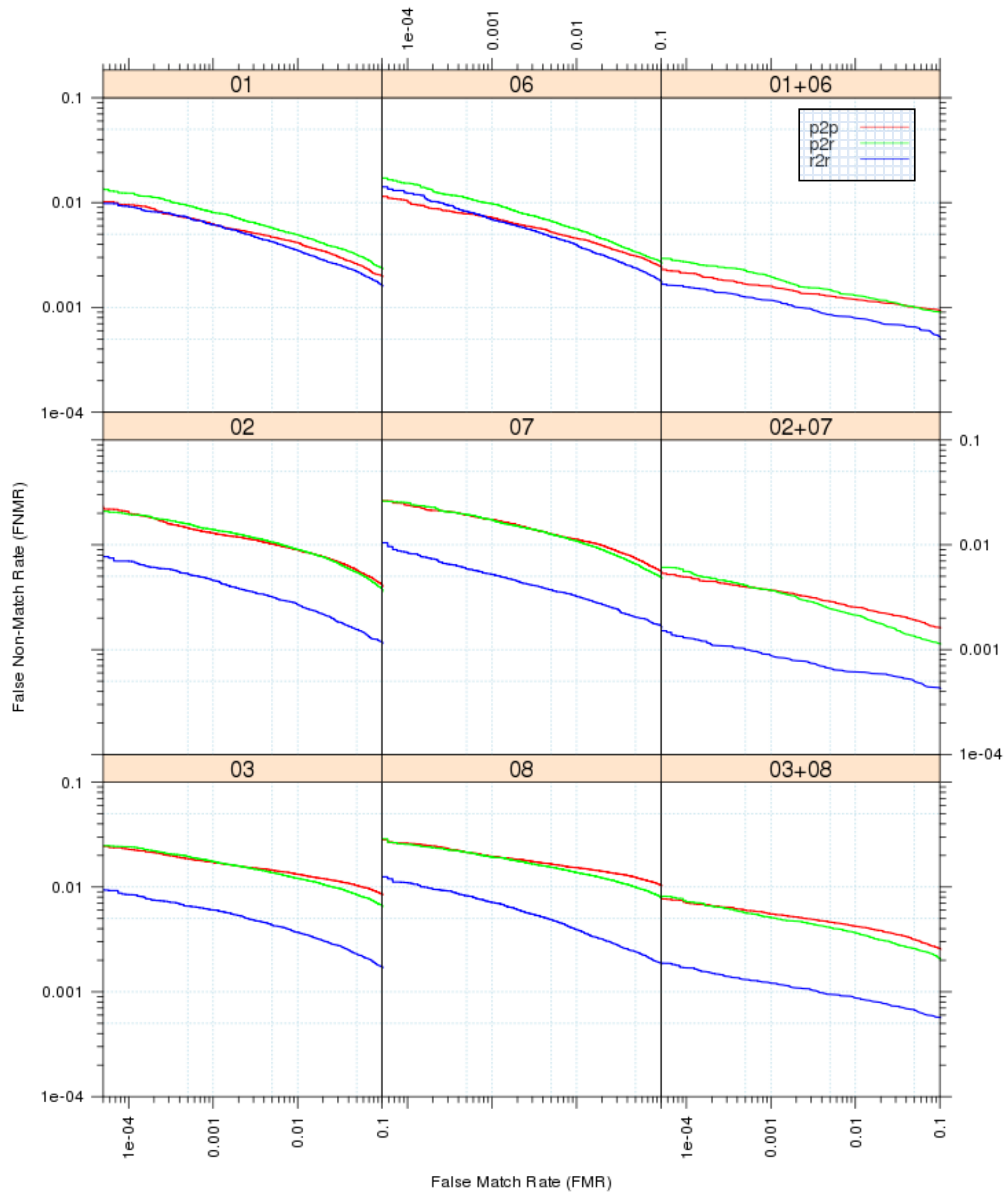

Figure 3A-4: DET for dataset AZLA 
Note: $p 2 p$ - plain vs. plain; $p 2 r$ - plain vs. rolled; r2r - rolled vs. rolled.

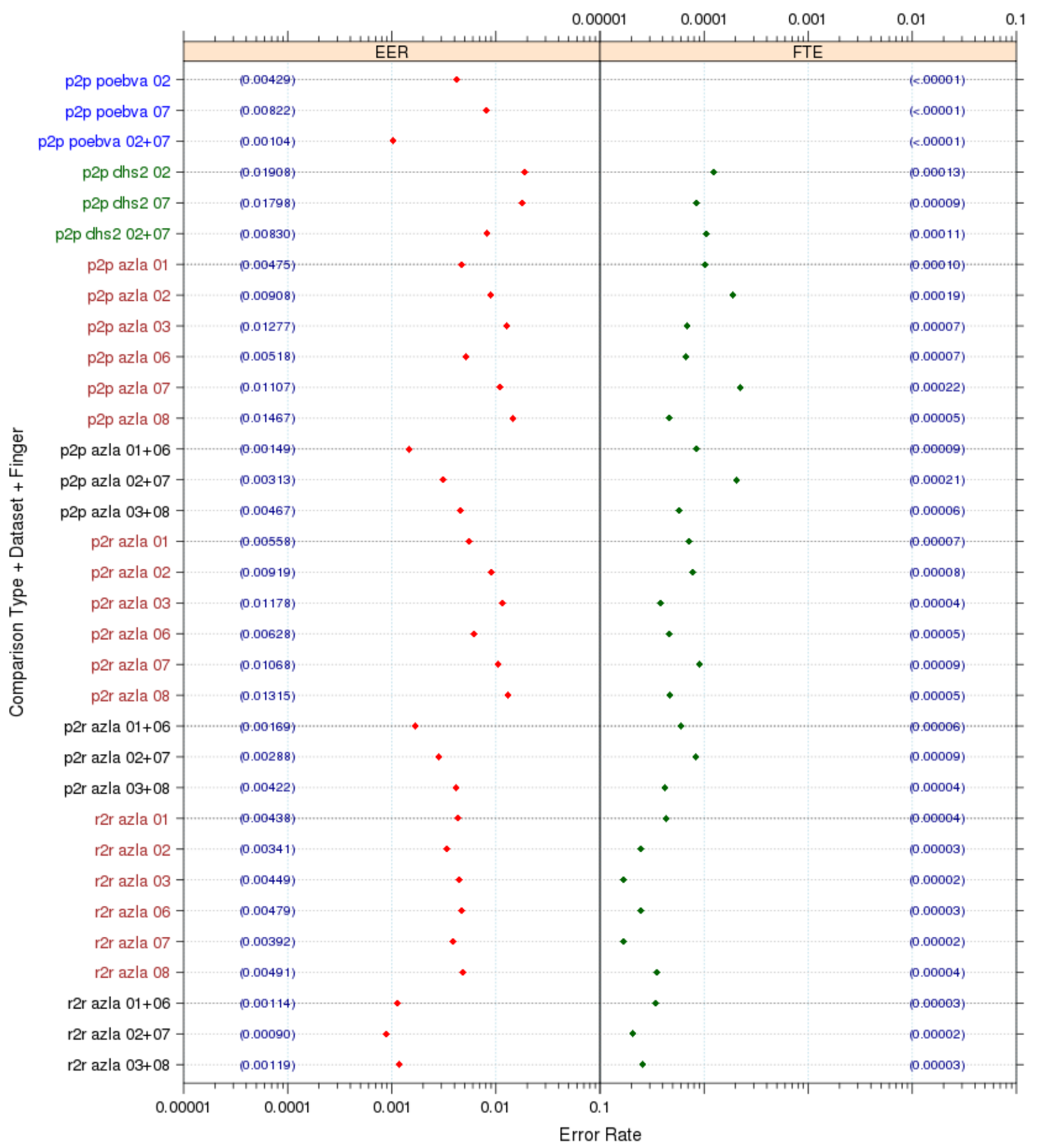

Figure 3A-5 EER and FTE
$3 A=$ Avalon Biometrics S.L.
$3 B=I D$ Solutions, Inc.
$3 \mathrm{C}=$ Patrima Technology Company 


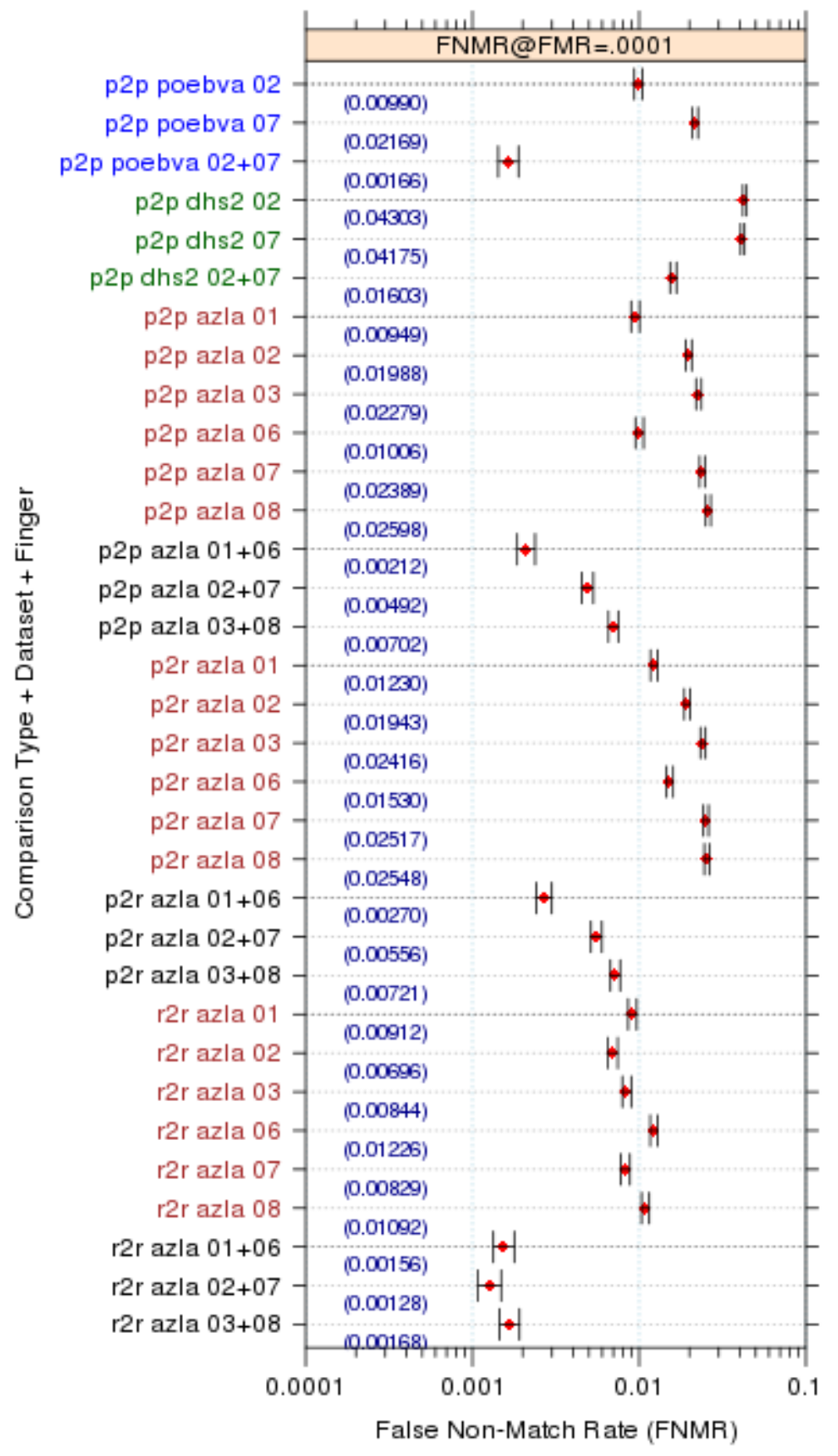

Figure 3A-6: FNMRs @ FMR = .0001 and 95\% Confidence Intervals 


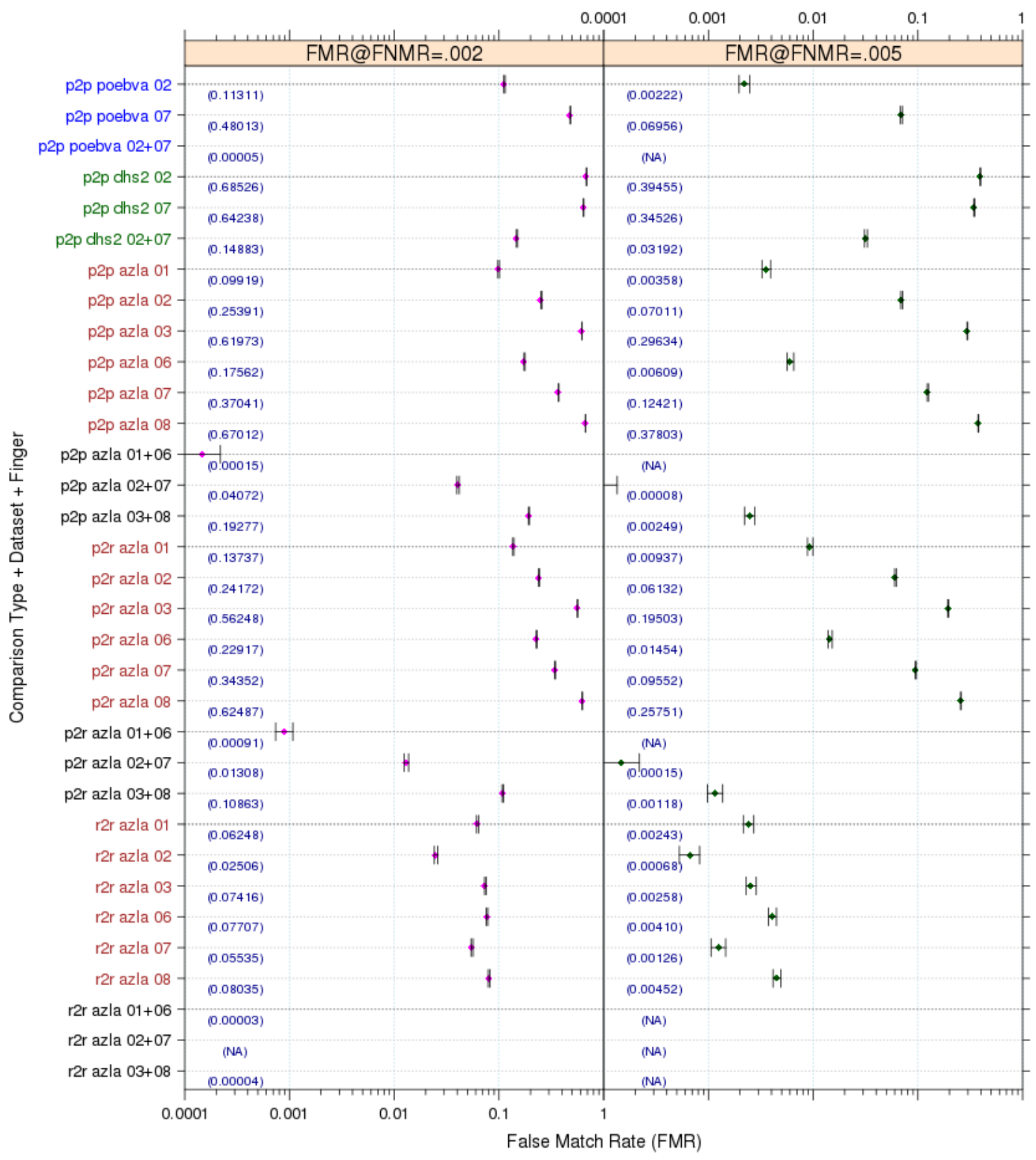

Figure 3A-7: FMRs@FNMR $=\{.002,0.005\}$ and 95\% Confidence Intervals

Note: NA - The number couldn't be reliably measured with the current sample size of 120,000 .

$3 \mathrm{~A}=$ Avalon Biometrics S.L. $\quad 3 B=$ ID Solutions, Inc

$3 \mathrm{C}=$ Patrima Technology Company

A-8 


\begin{tabular}{|c|c|c|c|c|c|}
\hline $\begin{array}{c}\text { Comparison } \\
\text { Type }\end{array}$ & Dataset & $\begin{array}{c}\text { Finger } \\
\text { position }\end{array}$ & EER & FTE Rate & $\begin{array}{l}\text { FTE } \\
\text { count }\end{array}$ \\
\hline $\mathrm{p} 2 \mathrm{p}$ & poebva & 02 & 0.004292 & 0.000003 & 1 \\
\hline p2p & poebva & 07 & 0.008225 & 0.000000 & 0 \\
\hline p2p & poebva & $02+07$ & 0.001042 & 0.000001 & 1 \\
\hline p2p & dhs2 & 02 & 0.020142 & 0.000125 & 45 \\
\hline p2p & dhs2 & 07 & 0.018942 & 0.000086 & 31 \\
\hline p2p & dhs2 & $02+07$ & 0.009308 & 0.000106 & 76 \\
\hline p2p & azla & 01 & 0.004750 & 0.000103 & 37 \\
\hline$p 2 p$ & azla & 02 & 0.009083 & 0.000192 & 69 \\
\hline p2p & azla & 03 & 0.012767 & 0.000069 & 25 \\
\hline p2p & azla & 06 & 0.005183 & 0.000067 & 24 \\
\hline p2p & azla & 07 & 0.011075 & 0.000225 & 81 \\
\hline p2p & azla & 08 & 0.014667 & 0.000047 & 17 \\
\hline p2p & azla & $01+06$ & 0.001492 & 0.000085 & 61 \\
\hline p2p & azla & $02+07$ & 0.003125 & 0.000208 & 150 \\
\hline p2p & azla & $03+08$ & 0.004667 & 0.000058 & 42 \\
\hline$p 2 r$ & azla & 01 & 0.005583 & 0.000072 & 26 \\
\hline p2r & azla & 02 & 0.009192 & 0.000078 & 28 \\
\hline p2r & azla & 03 & 0.011783 & 0.000039 & 14 \\
\hline p2r & azla & 06 & 0.006275 & 0.000047 & 17 \\
\hline p2r & azla & 07 & 0.010683 & 0.000092 & 33 \\
\hline$p 2 r$ & azla & 08 & 0.013150 & 0.000047 & 17 \\
\hline$p 2 r$ & azla & $01+06$ & 0.001692 & 0.000060 & 43 \\
\hline p2r & azla & $02+07$ & 0.002883 & 0.000085 & 61 \\
\hline p2r & azla & $03+08$ & 0.004217 & 0.000043 & 31 \\
\hline$r 2 r$ & azla & 01 & 0.004383 & 0.000044 & 16 \\
\hline$r 2 r$ & azla & 02 & 0.003408 & 0.000025 & 9 \\
\hline$r 2 r$ & azla & 03 & 0.004492 & 0.000017 & 6 \\
\hline$r 2 r$ & azla & 06 & 0.004792 & 0.000025 & 9 \\
\hline$r 2 r$ & azla & 07 & 0.003925 & 0.000017 & 6 \\
\hline$r 2 r$ & azla & 08 & 0.004908 & 0.000036 & 13 \\
\hline$r 2 r$ & azla & $01+06$ & 0.001142 & 0.000035 & 25 \\
\hline$r 2 r$ & azla & $02+07$ & 0.000900 & 0.000021 & 15 \\
\hline$r 2 r$ & azla & $03+08$ & 0.001192 & 0.000026 & 19 \\
\hline
\end{tabular}

Table 3A-3: EER and FTE table 


\begin{tabular}{|c|c|c|c|c|c|c|c|c|}
\hline $\begin{array}{c}\text { Matchin } \\
\text { g Type }\end{array}$ & Dataset & $\begin{array}{l}\text { Finger } \\
\text { position }\end{array}$ & $\begin{array}{c}\text { FNMR1@ } \\
\text { FMR= } \\
0.0001\end{array}$ & $\begin{array}{c}95 \% \\
\text { Confidenc } \\
\text { e Interval } \\
\text { of FNMR } \\
\end{array}$ & $\begin{array}{c}\text { FMR1 } \\
@ \\
\text { FNMR= } \\
0.002 \\
\end{array}$ & $\begin{array}{c}95 \% \\
\text { Confidence } \\
\text { Interval of } \\
\text { FMR1 } \\
\end{array}$ & $\begin{array}{c}\text { FMR2@ } \\
\text { FNMR= } \\
0.005\end{array}$ & $\begin{array}{c}95 \% \\
\text { Confidence } \\
\text { Interval of } \\
\text { FMR2 } \\
\end{array}$ \\
\hline p2p & poebva & 02 & 0.00990 & \pm 0.00056 & 0.11311 & \pm 0.001792 & 0.00223 & \pm 0.00026 \\
\hline p2p & poebva & 07 & 0.02169 & \pm 0.00082 & 0.48013 & \pm 0.002827 & 0.06956 & \pm 0.00143 \\
\hline p2p & poebva & $02+07$ & 0.00166 & \pm 0.00023 & 0.00005 & \pm 0.000040 & NA & NA \\
\hline p2p & dhs2 & 02 & 0.04423 & \pm 0.00116 & 0.91418 & \pm 0.001585 & 0.48573 & \pm 0.00282 \\
\hline $\mathrm{p} 2 \mathrm{p}$ & dhs2 & 07 & 0.04291 & \pm 0.00114 & 0.86804 & \pm 0.001915 & 0.44215 & \pm 0.00281 \\
\hline p2p & dhs2 & $02+07$ & 0.01724 & \pm 0.00073 & 0.63236 & \pm 0.002728 & 0.05437 & \pm 0.00128 \\
\hline p2p & azla & 01 & 0.00949 & \pm 0.00055 & 0.09919 & \pm 0.001691 & 0.00358 & \pm 0.00033 \\
\hline p2p & azla & 02 & 0.01988 & \pm 0.00079 & 0.25391 & \pm 0.002463 & 0.07011 & \pm 0.00144 \\
\hline p2p & azla & 03 & 0.02279 & \pm 0.00084 & 0.61973 & \pm 0.002747 & 0.29634 & \pm 0.00258 \\
\hline $\mathrm{p} 2 \mathrm{p}$ & azla & 06 & 0.01006 & \pm 0.00057 & 0.17562 & \pm 0.002153 & 0.00609 & \pm 0.00044 \\
\hline p2p & azla & 07 & 0.02389 & \pm 0.00086 & 0.37041 & \pm 0.002732 & 0.12421 & \pm 0.00186 \\
\hline $\mathrm{p} 2 \mathrm{p}$ & azla & 08 & 0.02598 & \pm 0.00090 & 0.67012 & \pm 0.002660 & 0.37803 & \pm 0.00274 \\
\hline p2p & azla & $01+06$ & 0.00212 & \pm 0.00026 & 0.00015 & \pm 0.000069 & NA & NA \\
\hline$p 2 p$ & azla & $02+07$ & 0.00492 & \pm 0.00039 & 0.04072 & \pm 0.001118 & 0.00008 & \pm 0.00005 \\
\hline p2p & azla & $03+08$ & 0.00702 & \pm 0.00047 & 0.19277 & \pm 0.002232 & 0.00249 & \pm 0.00028 \\
\hline $\mathrm{p} 2 \mathrm{r}$ & azla & 01 & 0.01230 & \pm 0.00062 & 0.13738 & \pm 0.001948 & 0.00938 & \pm 0.00054 \\
\hline p2r & azla & 02 & 0.01943 & \pm 0.00078 & 0.24173 & \pm 0.002422 & 0.06132 & \pm 0.00135 \\
\hline $\mathrm{p} 2 \mathrm{r}$ & azla & 03 & 0.02416 & \pm 0.00086 & 0.56248 & \pm 0.002807 & 0.19503 & \pm 0.00224 \\
\hline$p 2 r$ & azla & 06 & 0.01530 & \pm 0.00069 & 0.22917 & \pm 0.002378 & 0.01454 & \pm 0.00067 \\
\hline $\mathrm{p} 2 \mathrm{r}$ & azla & 07 & 0.02517 & \pm 0.00088 & 0.34352 & \pm 0.002687 & 0.09553 & \pm 0.00166 \\
\hline $\mathrm{p} 2 \mathrm{r}$ & azla & 08 & 0.02548 & \pm 0.00089 & 0.62488 & \pm 0.002739 & 0.25751 & \pm 0.00247 \\
\hline$p 2 r$ & azla & $01+06$ & 0.00270 & \pm 0.00029 & 0.00091 & \pm 0.00017 & NA & NA \\
\hline $\mathrm{p} 2 \mathrm{r}$ & azla & $02+07$ & 0.00556 & \pm 0.00042 & 0.01308 & \pm 0.000643 & 0.00015 & \pm 0.00006 \\
\hline p2r & azla & $03+08$ & 0.00721 & \pm 0.00047 & 0.10863 & \pm 0.001761 & 0.00118 & \pm 0.00019 \\
\hline $\mathrm{r} 2 \mathrm{r}$ & azla & 01 & 0.00913 & \pm 0.00053 & 0.06248 & \pm 0.001369 & 0.00243 & \pm 0.00027 \\
\hline $\mathrm{r} 2 \mathrm{r}$ & azla & 02 & 0.00696 & \pm 0.00047 & 0.02506 & \pm 0.000884 & 0.00068 & \pm 0.00014 \\
\hline $\mathrm{r} 2 \mathrm{r}$ & azla & 03 & 0.00844 & \pm 0.00051 & 0.07416 & \pm 0.001483 & 0.00258 & \pm 0.00028 \\
\hline $\mathrm{r} 2 \mathrm{r}$ & azla & 06 & 0.01226 & \pm 0.00062 & 0.07707 & \pm 0.001509 & 0.00410 & \pm 0.00036 \\
\hline$r 2 r$ & azla & 07 & 0.00829 & \pm 0.00051 & 0.05535 & \pm 0.001294 & 0.00126 & \pm 0.00020 \\
\hline $\mathrm{r} 2 \mathrm{r}$ & azla & 08 & 0.01092 & \pm 0.00058 & 0.08035 & \pm 0.001538 & 0.00452 & \pm 0.00037 \\
\hline $\mathrm{r} 2 \mathrm{r}$ & azla & $01+06$ & 0.00156 & \pm 0.00022 & 0.00003 & \pm 0.000028 & NA & NA \\
\hline $\mathrm{r} 2 \mathrm{r}$ & azla & $02+07$ & 0.00128 & \pm 0.00020 & NA & NA & NA & NA \\
\hline $\mathrm{r} 2 \mathrm{r}$ & azla & $03+08$ & 0.00168 & \pm 0.00023 & 0.00004 & \pm 0.000037 & NA & NA \\
\hline
\end{tabular}

Table 3A-4: FNMR@FMR=0.0001, FMRs@FNMR $=\{.002,0.005\}$ and $95 \%$ Confidence Intervals

Note: NA - The number couldn't be reliably measured with the current sample size of 120,000 . 


\section{Matcher 3B}

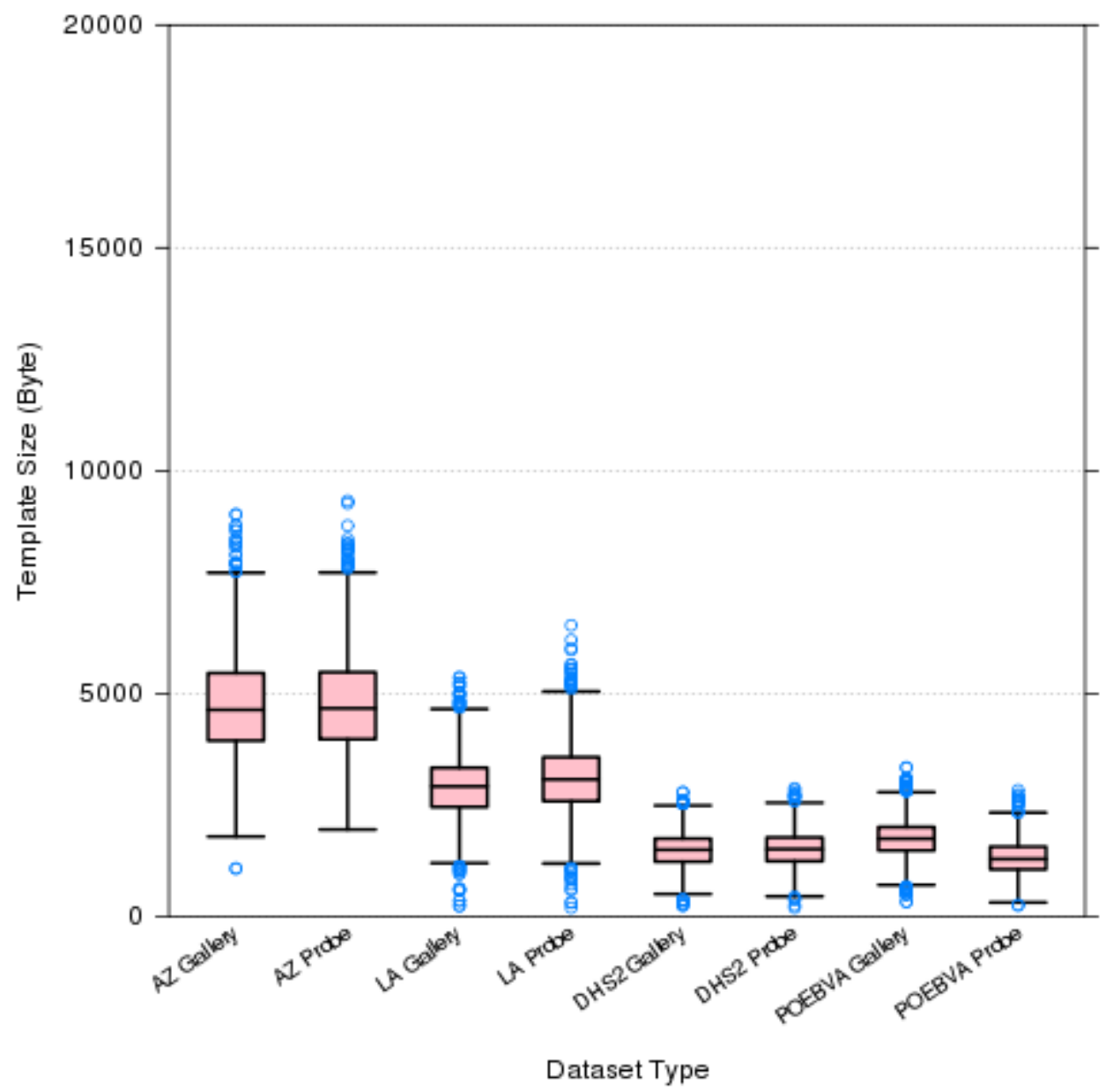

Figure 3B-1: 1K Sample Template Size Distribution

\begin{tabular}{|c|c|c|c|c|c|c|c|c|}
\hline Dataset & AZ & AZ & LA & LA & DHS2 & DHS2 & POEBVA & POEBVA \\
\hline $\begin{array}{c}\text { Type } \\
\text { Width } \times \text { Height } \\
\text { (pixels) }\end{array}$ & Gallery & Probe & Gallery & Probe & Gallery & Probe & Gallery & Probe \\
\hline & & $800 \times 800$ & $412 \times 1000$ & $400 \times 776$ & $368 \times 368$ & $368 \times 368$ & $500 \times 500$ & $368 \times 368$ \\
\hline Maximum & 9018 & 9324 & 5360 & 6529 & 2782 & 2872 & 3339 & 2830 \\
\hline $75 \%$ & 5458 & 5477 & 3333 & 3569 & 1743 & 1769 & 2003 & 1562 \\
\hline Median & 4633 & 4666 & 2914 & 3072 & 1492 & 1507 & 1742 & 1284 \\
\hline $25 \%$ & 3941 & 3973 & 2452 & 2584 & 1225 & 1237 & 1475 & 1052 \\
\hline Minimum & 1072 & 1946 & 233 & 191 & 240 & 191 & 326 & 241 \\
\hline
\end{tabular}

Table 3B-1: Template Size (Byte) 

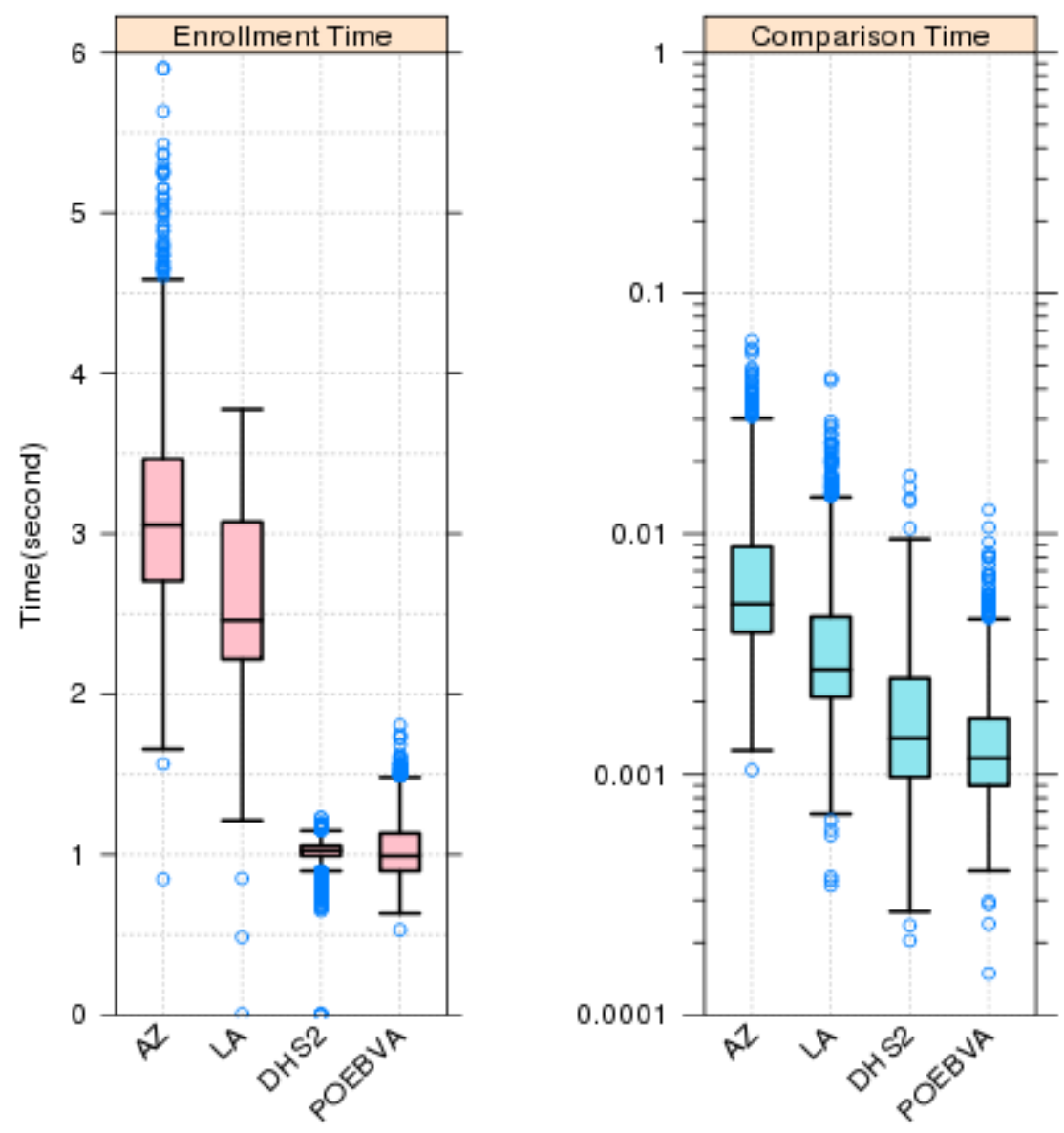

Figure 3B-2: 1K Sample Enrollment and Comparison Time

Enrollment Time (second)

\begin{tabular}{|c|c|c|c|c|}
\hline Dataset & AZ & LA & DHS2 & POEBVA \\
\hline & & & & \\
\hline Maximum & 5.9013 & 3.7762 & 1.2305 & 1.8059 \\
\hline $75 \%$ & 3.4654 & 3.0734 & 1.0557 & 1.1325 \\
\hline Median & 3.0539 & 2.4603 & 1.0260 & 0.9923 \\
\hline $25 \%$ & 2.7068 & 2.2169 & 0.9924 & 0.8975 \\
\hline Minimum & 0.8461 & 0.0056 & 0.0027 & 0.5310 \\
\hline
\end{tabular}

Comparison Time (second)

\begin{tabular}{|c|c|c|c|c|}
\hline Dataset & AZ & LA & DHS2 & POEBVA \\
\hline & & & & \\
\hline Maximum & 0.06350 & 0.04454 & 0.0174 & 0.0126 \\
\hline $75 \%$ & 0.00885 & 0.00451 & 0.0025 & 0.0017 \\
\hline Median & 0.00511 & 0.00273 & 0.0014 & 0.0012 \\
\hline $25 \%$ & 0.00389 & 0.00209 & 0.0010 & 0.0009 \\
\hline Minimum & 0.00104 & 0.00035 & 0.0002 & 0.0001 \\
\hline
\end{tabular}

Table 3B-2: Enrollment and Comparison Time (second) 


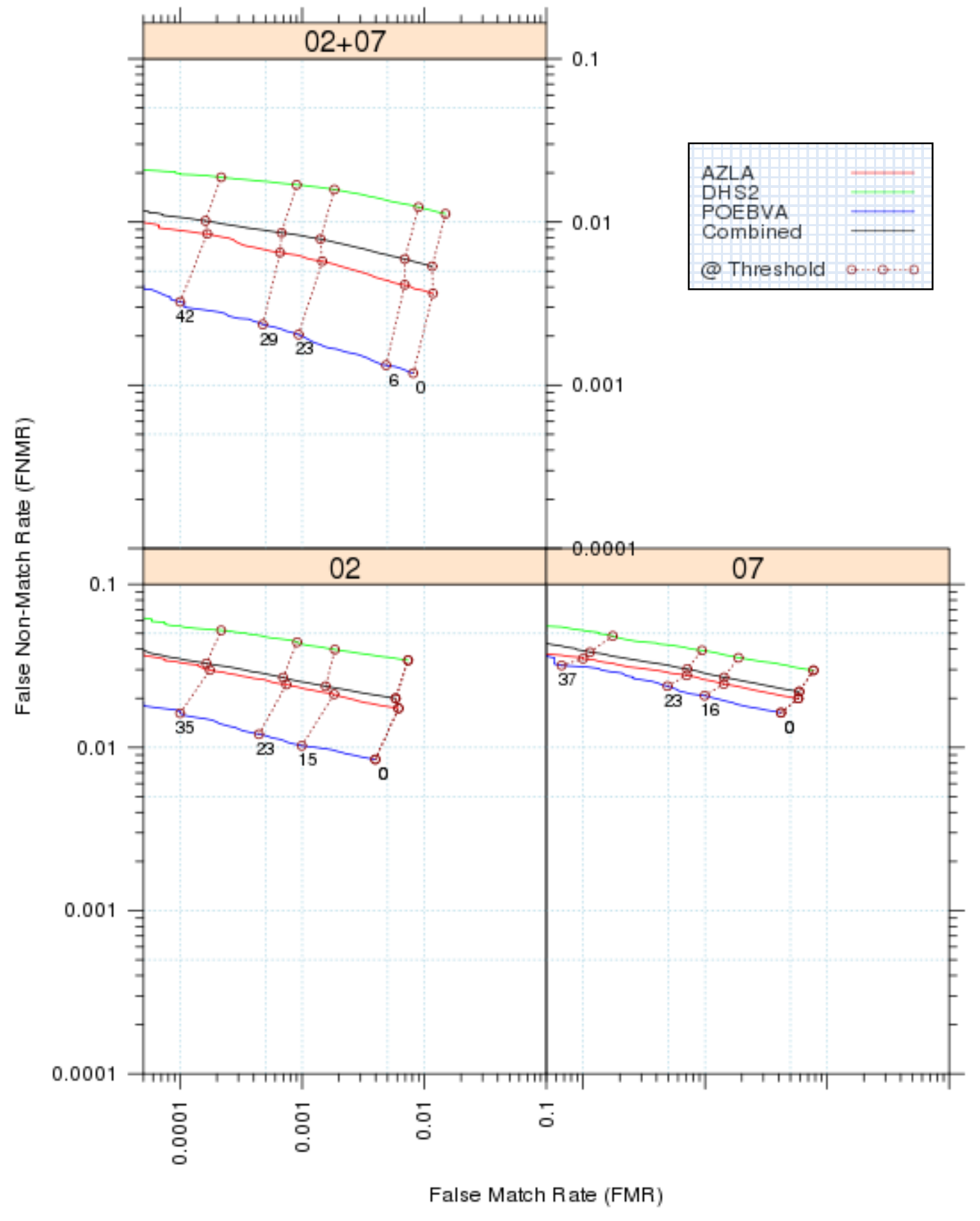

Figure 3B-3: DET for ALL Datasets (P2P) 


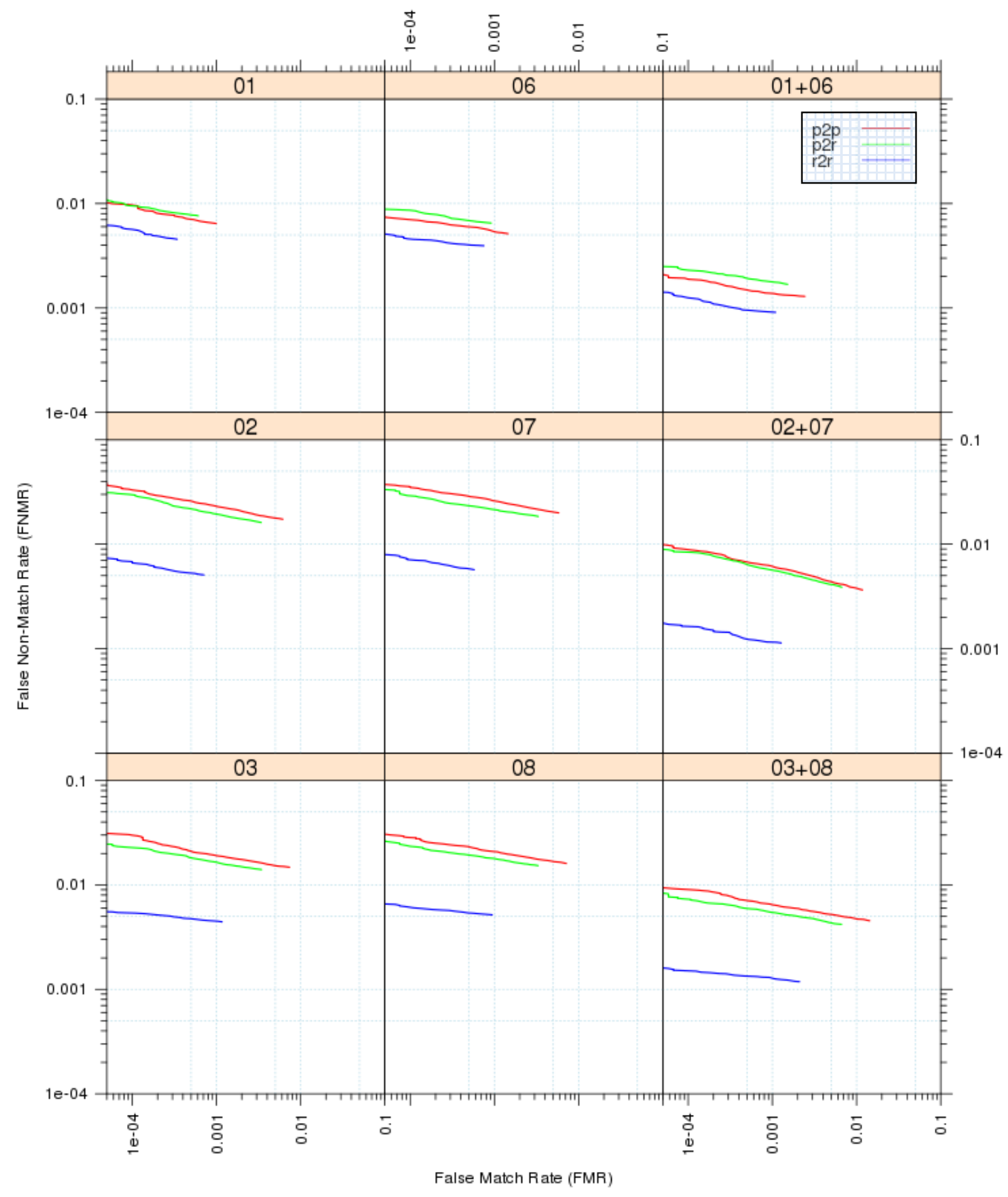

Figure 3B-4: DET for dataset AZLA

Note: $p 2 p$ - plain vs. plain; $p 2 r$ - plain vs. rolled; $r 2 r$ - rolled vs. rolled. 


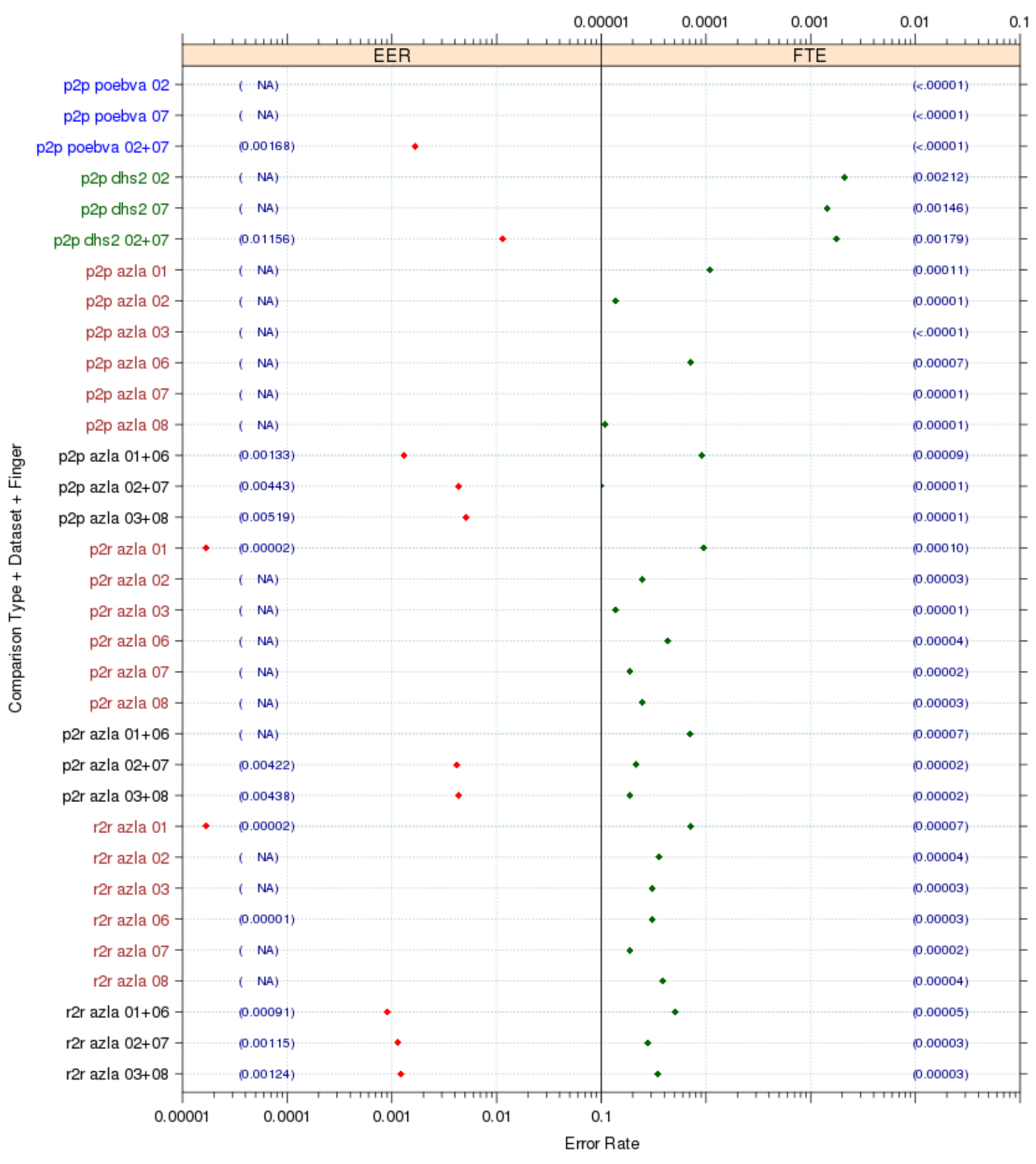

Figure 3B-5: EER and FTE

Note: NA - Could not obtain EER due to the minimum of FNMR is greater than the maximum of FMR (Figure 3B - 4). 


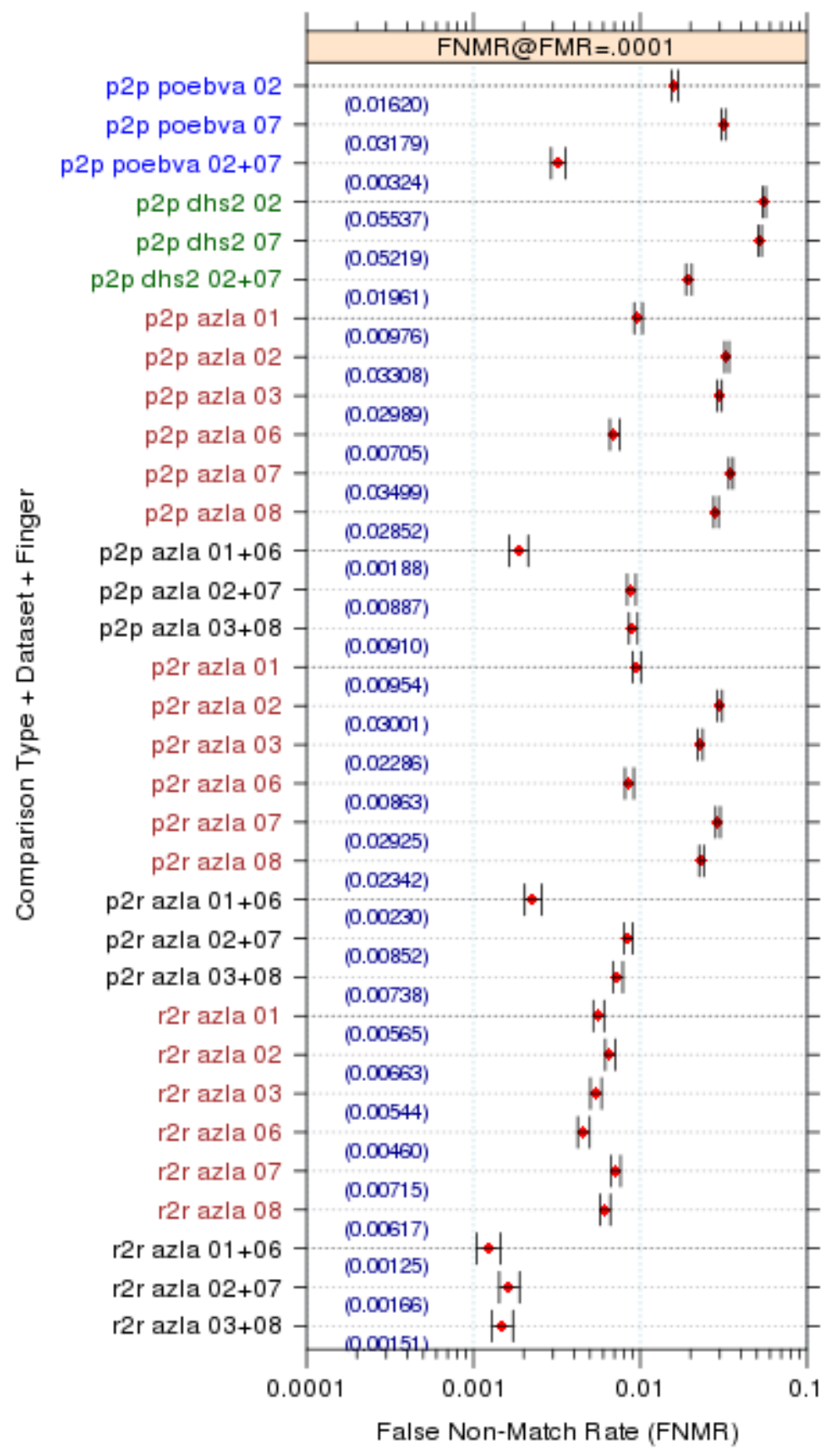

Figure 3B-6: FNMRs @ FMR = .0001 and 95\% Confidence Intervals 


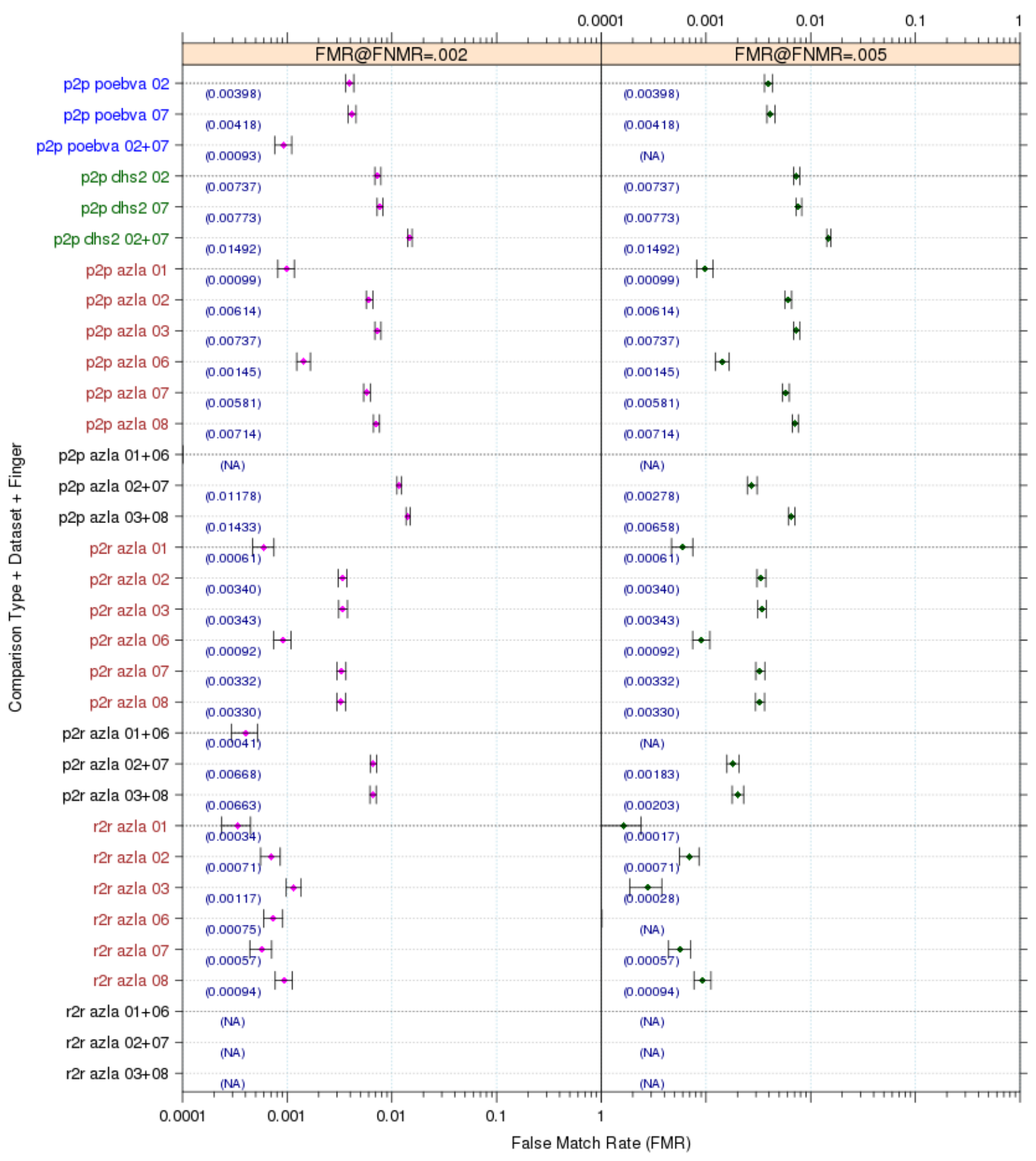

Figure 3B-7: FMRs @ FNMR $=\{.002,0.005\}$ and 95\% Confidence Intervals

Note: NA - The number couldn't be reliably measured with the current sample size of 120,000 . 


\begin{tabular}{|c|c|c|c|c|c|}
\hline $\begin{array}{c}\text { Comparison } \\
\text { Type }\end{array}$ & Dataset & $\begin{array}{c}\text { Finger } \\
\text { Position }\end{array}$ & EER & FTE Rate & FTE count \\
\hline p2p & poebva & 02 & 0.004292 & 0.000003 & 1 \\
\hline p2p & poebva & 07 & 0.008225 & 0.000000 & 0 \\
\hline p2p & poebva & $02+07$ & 0.001042 & 0.000001 & 1 \\
\hline p2p & dhs2 & 02 & NA & 0.00212 & $762^{* *}$ \\
\hline p2p & dhs2 & 07 & NA & 0.00146 & $524^{* *}$ \\
\hline p2p & dhs2 & $02+07$ & 0.0116 & 0.00179 & $1286^{* *}$ \\
\hline p2p & azla & 01 & $N^{*}$ & 0.00011 & 40 \\
\hline p2p & azla & 02 & NA & 0.00001 & 5 \\
\hline p2p & azla & 03 & NA & 0.00000 & 0 \\
\hline$p 2 p$ & azla & 06 & NA & 0.00007 & 26 \\
\hline p2p & azla & 07 & NA & 0.00001 & 2 \\
\hline p2p & azla & 08 & NA & 0.00001 & 4 \\
\hline p2p & azla & $01+06$ & 0.0013 & 0.00009 & 66 \\
\hline p2p & azla & $02+07$ & 0.0044 & 0.00001 & 7 \\
\hline p2p & azla & $03+08$ & 0.0052 & 0.00001 & 4 \\
\hline$p 2 r$ & azla & 01 & NA & 0.00010 & 35 \\
\hline $\mathrm{p} 2 \mathrm{r}$ & azla & 02 & NA & 0.00003 & 9 \\
\hline $\mathrm{p} 2 \mathrm{r}$ & azla & 03 & NA & 0.00001 & 5 \\
\hline$p 2 r$ & azla & 06 & NA & 0.00004 & 16 \\
\hline $\mathrm{p} 2 \mathrm{r}$ & azla & 07 & NA & 0.00002 & 7 \\
\hline $\mathrm{p} 2 \mathrm{r}$ & azla & 08 & NA & 0.00003 & 9 \\
\hline$p 2 r$ & azla & $01+06$ & NA & 0.00007 & 51 \\
\hline $\mathrm{p} 2 \mathrm{r}$ & azla & $02+07$ & 0.0042 & 0.00002 & 16 \\
\hline$p 2 r$ & azla & $03+08$ & 0.0044 & 0.00002 & 14 \\
\hline $\mathrm{r} 2 \mathrm{r}$ & azla & 01 & NA & 0.00007 & 26 \\
\hline r2r & azla & 02 & NA & 0.00004 & 13 \\
\hline$r 2 r$ & azla & 03 & NA & 0.00003 & 11 \\
\hline$r 2 r$ & azla & 06 & NA & 0.00003 & 11 \\
\hline$r 2 r$ & azla & 07 & NA & 0.00002 & 7 \\
\hline$r 2 r$ & azla & 08 & NA & 0.00004 & 14 \\
\hline$r 2 r$ & azla & $01+06$ & 0.0009 & 0.00005 & 37 \\
\hline $\mathrm{r} 2 \mathrm{r}$ & azla & $02+07$ & 0.0012 & 0.00003 & 20 \\
\hline$r 2 r$ & azla & $03+08$ & 0.0012 & 0.00004 & 25 \\
\hline
\end{tabular}

Table 3B-3: EER and FTE table

Note: *NA Could not obtain EER due to the minimal FNMR is greater than the maximal of FMR (Fig 4).

** Could not enroll when the images were very low contrast. 


\begin{tabular}{|c|c|c|c|c|c|c|c|c|}
\hline $\begin{array}{l}\text { Matching } \\
\text { Type }\end{array}$ & Dataset & $\begin{array}{l}\text { Finger } \\
\text { position }\end{array}$ & $\begin{array}{c}\text { FNMR@ } \\
\text { FMR= } \\
0.0001\end{array}$ & $\begin{array}{c}95 \% \\
\text { Confidence } \\
\text { Interval of } \\
\text { FNMR } \\
\end{array}$ & $\begin{array}{c}\text { FMR1 @ } \\
\text { FNMR= } \\
0.002\end{array}$ & $\begin{array}{c}95 \% \\
\text { Confidence } \\
\text { Interval of } \\
\text { FMR1 } \\
\end{array}$ & $\begin{array}{c}\text { FMR2 @ } \\
\text { FNMR= } \\
0.005\end{array}$ & $\begin{array}{c}95 \% \\
\text { Confidence } \\
\text { Interval of } \\
\text { FMR2 } \\
\end{array}$ \\
\hline p2p & poebva & 02 & 0.016200 & \pm 0.00071 & 0.0040 & \pm 0.00036 & 0.0040 & \pm 0.00036 \\
\hline p2p & poebva & 07 & 0.031792 & \pm 0.00099 & 0.0042 & \pm 0.00037 & 0.0042 & \pm 0.00037 \\
\hline p2p & poebva & $02+07$ & 0.003242 & \pm 0.00032 & 0.00001 & \pm 0.00002 & 0.00001 & \pm 0.00002 \\
\hline $\mathrm{p} 2 \mathrm{p}$ & dhs2 & 02 & 0.055367 & \pm 0.00129 & 0.0074 & \pm 0.00048 & 0.0074 & \pm 0.00048 \\
\hline $\mathrm{p} 2 \mathrm{p}$ & dhs2 & 07 & 0.052192 & \pm 0.00126 & 0.0077 & \pm 0.00050 & 0.0077 & \pm 0.00050 \\
\hline $\mathrm{p} 2 \mathrm{p}$ & dhs2 & $02+07$ & 0.019608 & \pm 0.00078 & 0.0149 & \pm 0.00069 & 0.0149 & \pm 0.00069 \\
\hline$p 2 p$ & azla & 01 & 0.009758 & \pm 0.00056 & 0.0010 & \pm 0.00018 & 0.0010 & \pm 0.00018 \\
\hline p2p & azla & 02 & 0.033075 & \pm 0.00101 & 0.0061 & \pm 0.00044 & 0.0061 & \pm 0.00044 \\
\hline $\mathrm{p} 2 \mathrm{p}$ & azla & 03 & 0.029892 & \pm 0.00096 & 0.0074 & \pm 0.00048 & 0.0074 & \pm 0.00048 \\
\hline p2p & azla & 06 & 0.007050 & \pm 0.00047 & 0.0015 & \pm 0.00022 & 0.0015 & \pm 0.00022 \\
\hline p2p & azla & 07 & 0.034992 & \pm 0.00104 & 0.0058 & \pm 0.00043 & 0.0058 & \pm 0.00043 \\
\hline p2p & azla & 08 & 0.028517 & \pm 0.00094 & 0.0071 & \pm 0.00048 & 0.0071 & \pm 0.00048 \\
\hline p2p & azla & $01+06$ & 0.001883 & \pm 0.00025 & NA & NA & NA & NA \\
\hline p2p & azla & $02+07$ & 0.008875 & \pm 0.00053 & 0.0028 & \pm 0.00030 & 0.0028 & \pm 0.00030 \\
\hline p2p & azla & $03+08$ & 0.009100 & \pm 0.00054 & 0.0066 & \pm 0.00046 & 0.0066 & \pm 0.00046 \\
\hline $\mathrm{p} 2 \mathrm{r}$ & azla & 01 & 0.009542 & \pm 0.00055 & 0.0006 & \pm 0.00014 & 0.0006 & \pm 0.00014 \\
\hline $\mathrm{p} 2 \mathrm{r}$ & azla & 02 & 0.030008 & \pm 0.00097 & 0.0034 & \pm 0.00033 & 0.0034 & \pm 0.00033 \\
\hline $\mathrm{p} 2 \mathrm{r}$ & azla & 03 & 0.022858 & \pm 0.00085 & 0.0034 & \pm 0.00033 & 0.0034 & \pm 0.00033 \\
\hline $\mathrm{p} 2 \mathrm{r}$ & azla & 06 & 0.008625 & \pm 0.00052 & 0.0009 & \pm 0.00017 & 0.0009 & \pm 0.00017 \\
\hline $\mathrm{p} 2 \mathrm{r}$ & azla & 07 & 0.029250 & \pm 0.00095 & 0.0033 & \pm 0.00033 & 0.0033 & \pm 0.00033 \\
\hline $\mathrm{p} 2 \mathrm{r}$ & azla & 08 & 0.023417 & \pm 0.00086 & 0.0033 & \pm 0.00032 & 0.0033 & \pm 0.00032 \\
\hline $\mathrm{p} 2 \mathrm{r}$ & azla & $01+06$ & 0.002300 & \pm 0.00027 & NA & NA & NA & NA \\
\hline $\mathrm{p} 2 \mathrm{r}$ & azla & $02+07$ & 0.008517 & \pm 0.00052 & 0.0018 & \pm 0.00024 & 0.0018 & \pm 0.00024 \\
\hline $\mathrm{p} 2 \mathrm{r}$ & azla & $03+08$ & 0.007383 & \pm 0.00048 & 0.0020 & \pm 0.00026 & 0.0020 & \pm 0.00026 \\
\hline $\mathrm{r} 2 \mathrm{r}$ & azla & 01 & 0.005650 & \pm 0.00042 & 0.0002 & \pm 0.00007 & 0.0002 & \pm 0.00007 \\
\hline $\mathrm{r} 2 \mathrm{r}$ & azla & 02 & 0.006633 & \pm 0.00046 & 0.0007 & \pm 0.00015 & 0.0007 & \pm 0.00015 \\
\hline $\mathrm{r} 2 \mathrm{r}$ & azla & 03 & 0.005442 & \pm 0.00042 & 0.0003 & \pm 0.00010 & 0.0003 & \pm 0.00010 \\
\hline $\mathrm{r} 2 \mathrm{r}$ & azla & 06 & 0.0046 & \pm 0.00038 & 0.0001 & \pm 0.00004 & 0.0001 & \pm 0.00004 \\
\hline $\mathrm{r} 2 \mathrm{r}$ & azla & 07 & 0.007150 & \pm 0.00048 & 0.0006 & \pm 0.00014 & 0.0006 & \pm 0.00014 \\
\hline$r 2 r$ & azla & 08 & 0.006175 & \pm 0.00044 & 0.0009 & \pm 0.00017 & 0.0009 & \pm 0.00017 \\
\hline$r 2 r$ & azla & $01+06$ & 0.001250 & \pm 0.00020 & NA & NA & NA & NA \\
\hline $\mathrm{r} 2 \mathrm{r}$ & azla & $02+07$ & 0.001658 & \pm 0.00023 & NA & NA & NA & NA \\
\hline$r 2 r$ & azla & $03+08$ & 0.001508 & \pm 0.00022 & $\mathrm{NA}$ & $\mathrm{NA}$ & NA & $\mathrm{NA}$ \\
\hline
\end{tabular}

Table 3B-4: FNMR@ FMR=0.0001, FMRs@ FNMR = $\{.002,0.005\}$ and 95\% Confidence Intervals

Note: NA - The number couldn't be reliably measured with the current sample size of 120,000.

$3 A=$ Avalon Biometrics S.L. $\quad 3 B=$ ID Solutions, Inc. $\quad 3 C=$ Patrima Technology Company 


\section{Matcher 3C}

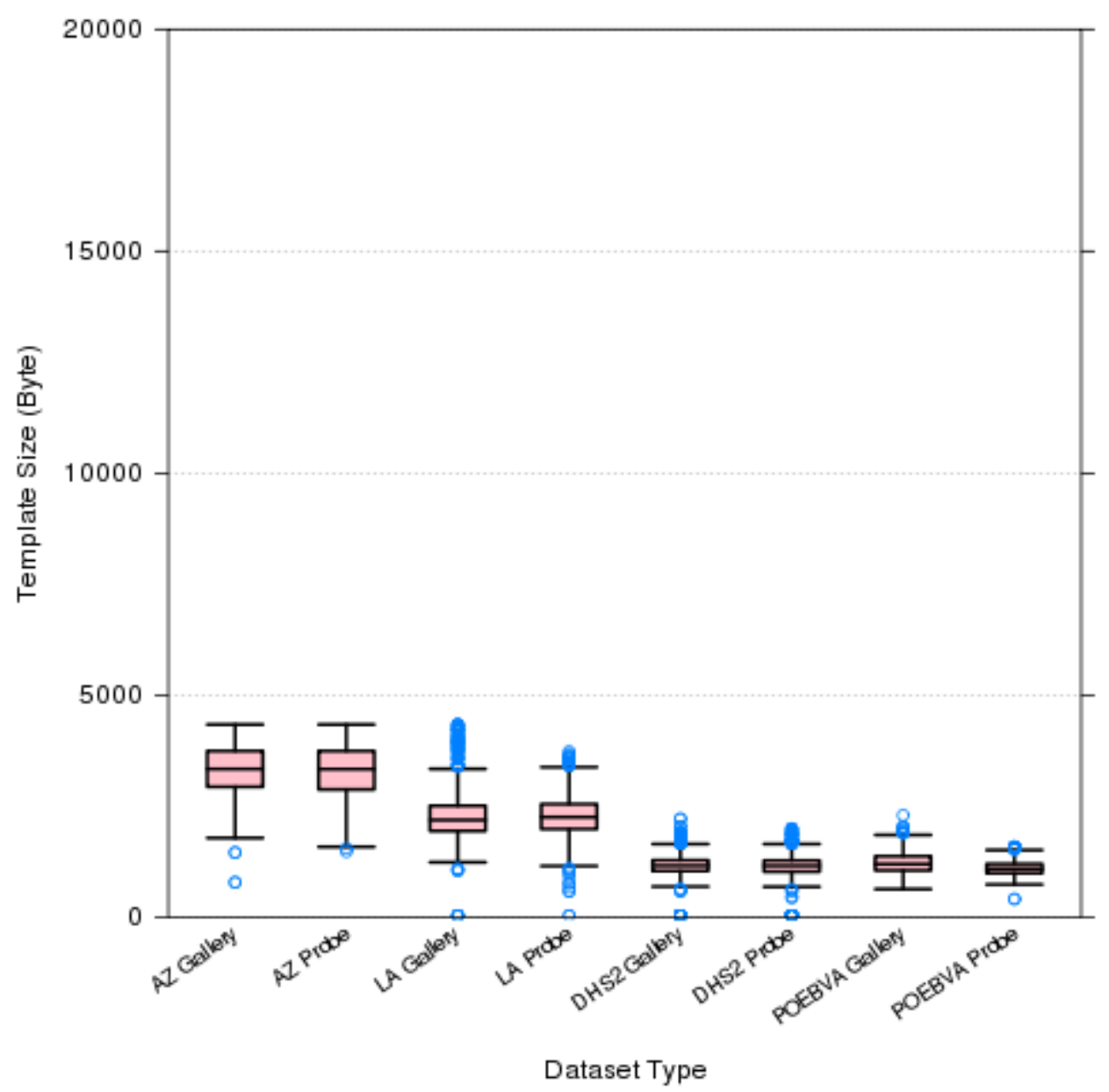

Figure 3C-1: 1K Sample Template Size Distribution

\begin{tabular}{|c|c|c|c|c|c|c|c|c|}
\hline Dataset & $\mathrm{AZ}$ & $\mathrm{AZ}$ & LA & LA & DHS2 & DHS2 & POEBVA & POEBVA \\
\hline Type & Gallery & Probe & Gallery & Probe & Gallery & Probe & Gallery & Probe \\
\hline $\begin{array}{c}\text { WidthxHeight } \\
\text { (pixels) }\end{array}$ & $800 \times 800$ & $800 \times 800$ & $412 \times 1000$ & $400 \times 776$ & $368 \times 368$ & $368 \times 368$ & $500 \times 500$ & $368 \times 368$ \\
\hline & & & & & & & & \\
\hline Maximum & 4336 & 4336 & 4336 & 3728 & 2212 & 1996 & 2292 & 1584 \\
\hline $75 \%$ & 3740 & 3740 & 2506 & 2544 & 1280 & 1272 & 1368 & 1196 \\
\hline Median & 3334 & 3330 & 2184 & 2250 & 1156 & 1152 & 1192 & 1088 \\
\hline $25 \%$ & 2932 & 2872 & 1938 & 1980 & 1036 & 1020 & 1048 & 988 \\
\hline Minimum & 780 & 1472 & 32 & 32 & 32 & 32 & 628 & 404 \\
\hline
\end{tabular}

Table 3C-1: Template Size (Byte) 

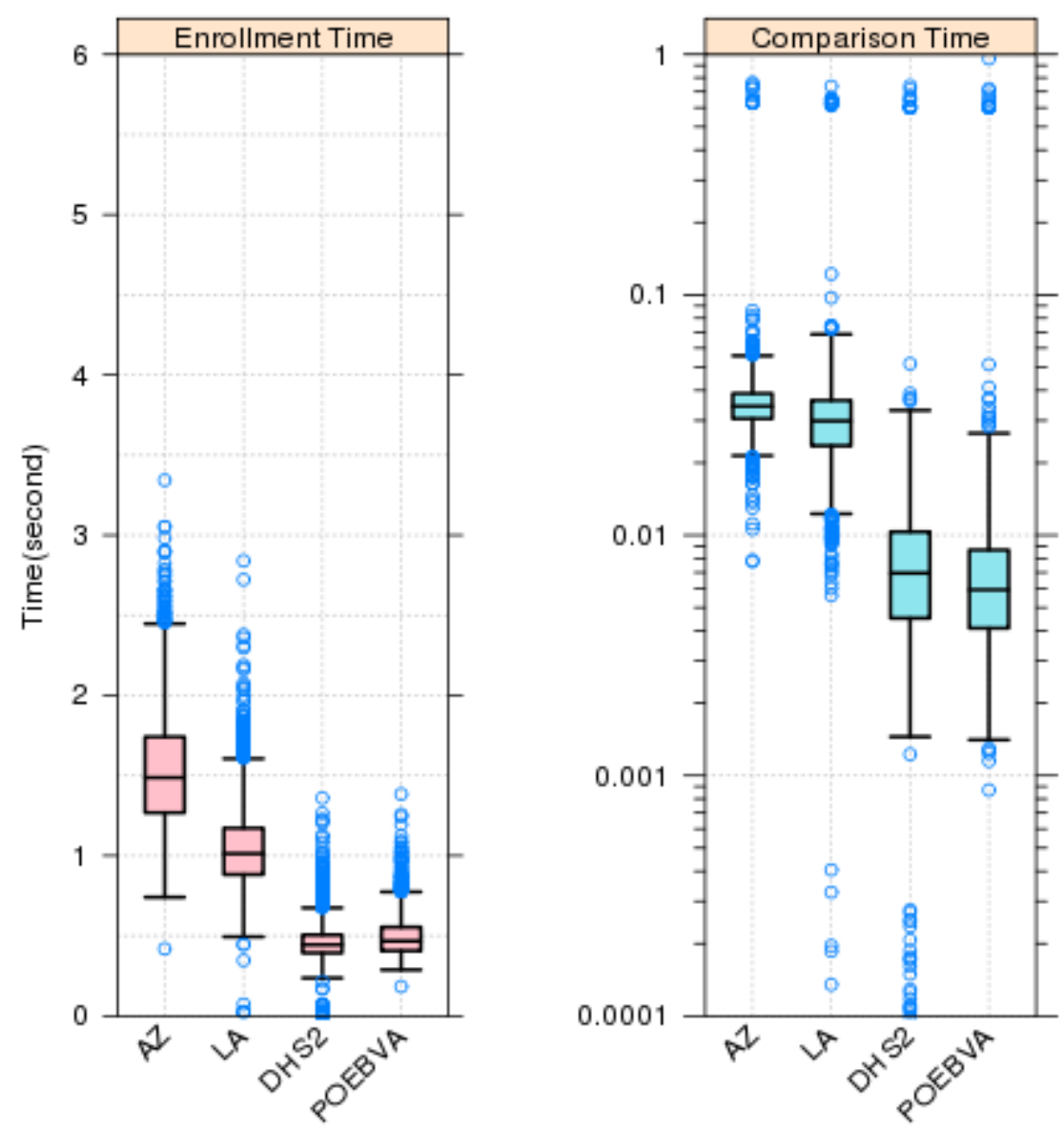

Figure 3C-2: 1K Sample Enrollment and Comparison Time

Enrollment Time (second)

\begin{tabular}{|c|c|c|c|c|}
\hline Dataset & AZ & LA & DHS2 & POEBVA \\
\hline & & & & \\
\hline Maximum & 3.3429 & 2.8403 & 1.3596 & 1.3840 \\
\hline $75 \%$ & 1.7416 & 1.1718 & 0.5060 & 0.5542 \\
\hline Median & 1.4869 & 1.0129 & 0.4444 & 0.4673 \\
\hline $25 \%$ & 1.2677 & 0.8824 & 0.3930 & 0.4064 \\
\hline Minimum & 0.4188 & 0.0195 & 0.0076 & 0.1833 \\
\hline
\end{tabular}

Comparison Time (second)

\begin{tabular}{|c|c|c|c|c|}
\hline Dataset & AZ & LA & DHS2 & POEBVA \\
\hline & & & & \\
\hline Maximum & 0.7627 & 0.7373 & 0.7415 & 0.9595 \\
\hline $75 \%$ & 0.0388 & 0.0364 & 0.0103 & 0.0087 \\
\hline Median & 0.0344 & 0.0299 & 0.0070 & 0.0059 \\
\hline $25 \%$ & 0.0305 & 0.0235 & 0.0045 & 0.0041 \\
\hline Minimum & 0.0078 & 0.0000 & 0.0000 & 0.0009 \\
\hline
\end{tabular}

Table 3C-2: Enrollment and Comparison Time (second)
$3 C=$ Patrima Technology Company 


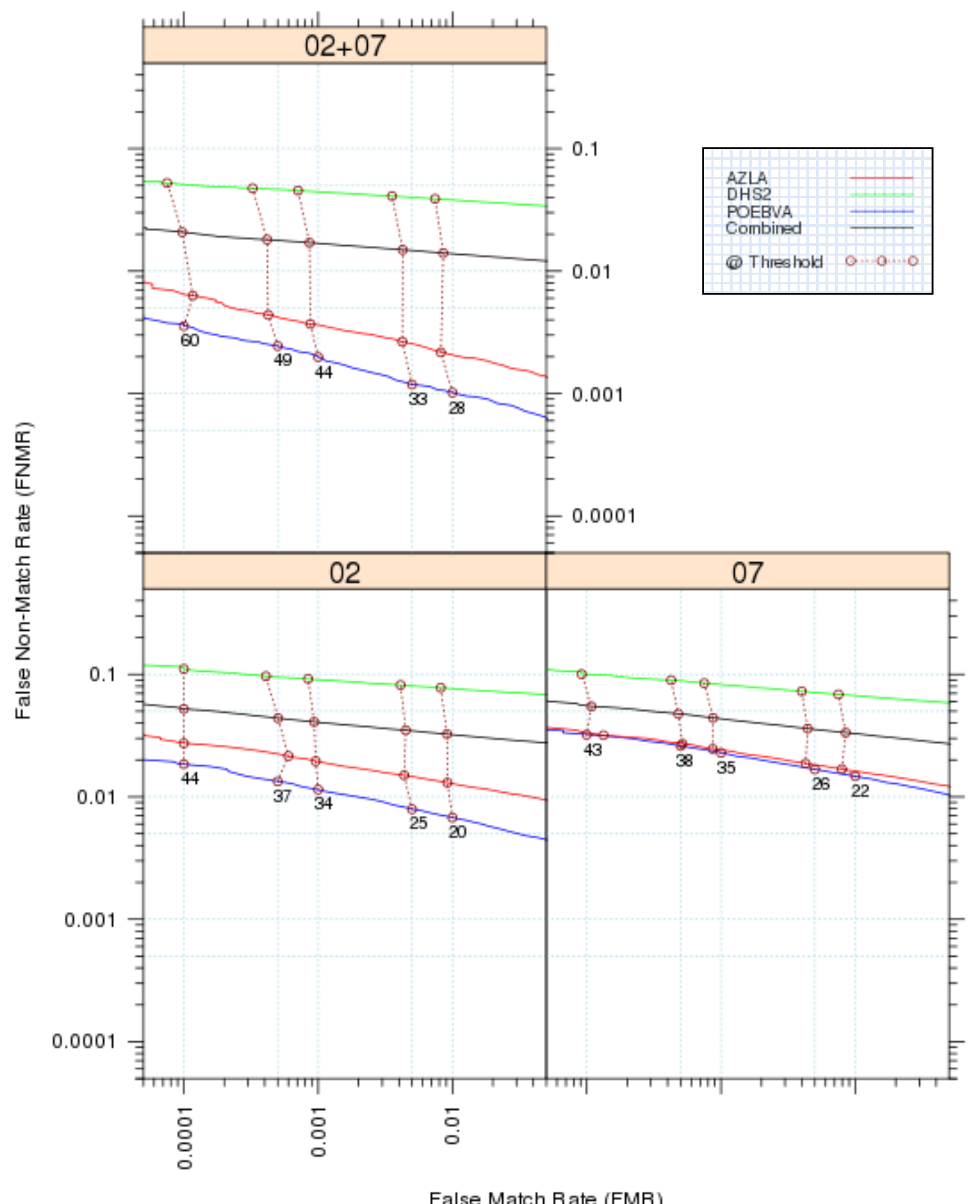

False Match Rate (FMR)

Figure 3C-3: DET for ALL Datasets (P2P) 


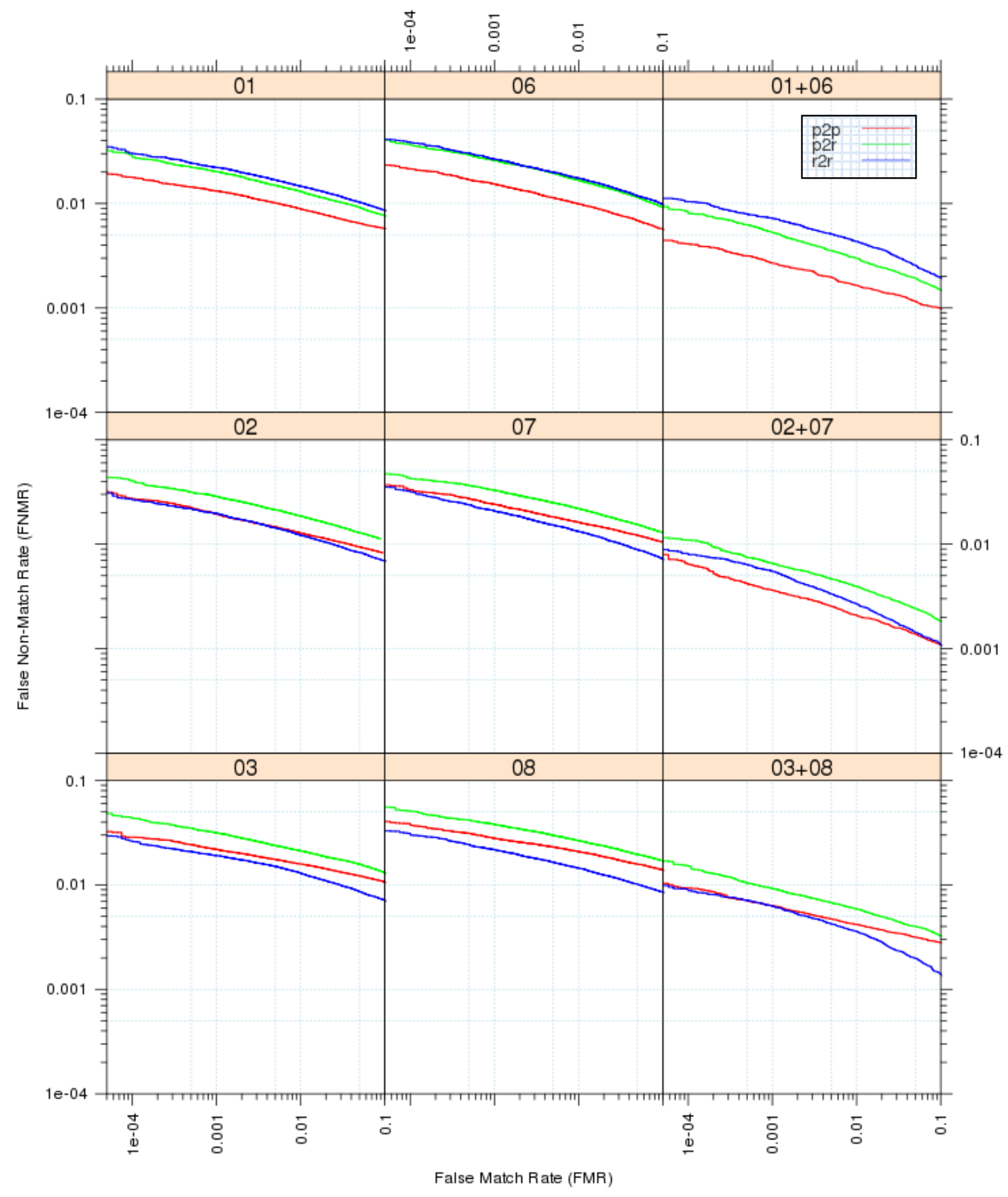

Figure 3C-4: DET for dataset AZLA

Note: $p 2 p$ - plain vs. plain; p2r - plain vs. rolled; $r 2 r$ - rolled vs. rolled. 


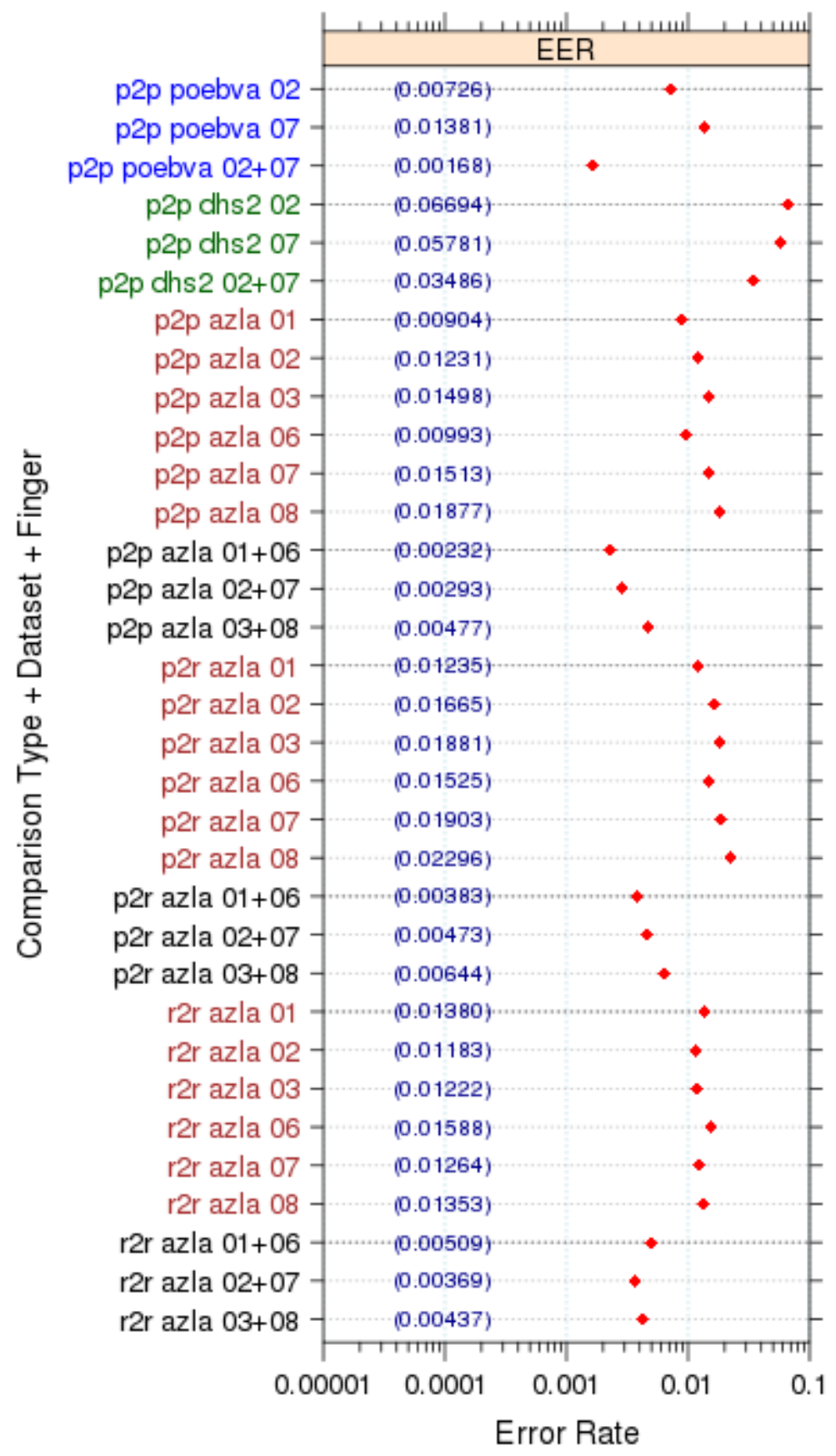

Figure 3C-5: EER and FTE

Note: EER table is not presented in Figure 5 due to all the EER $=0$. 


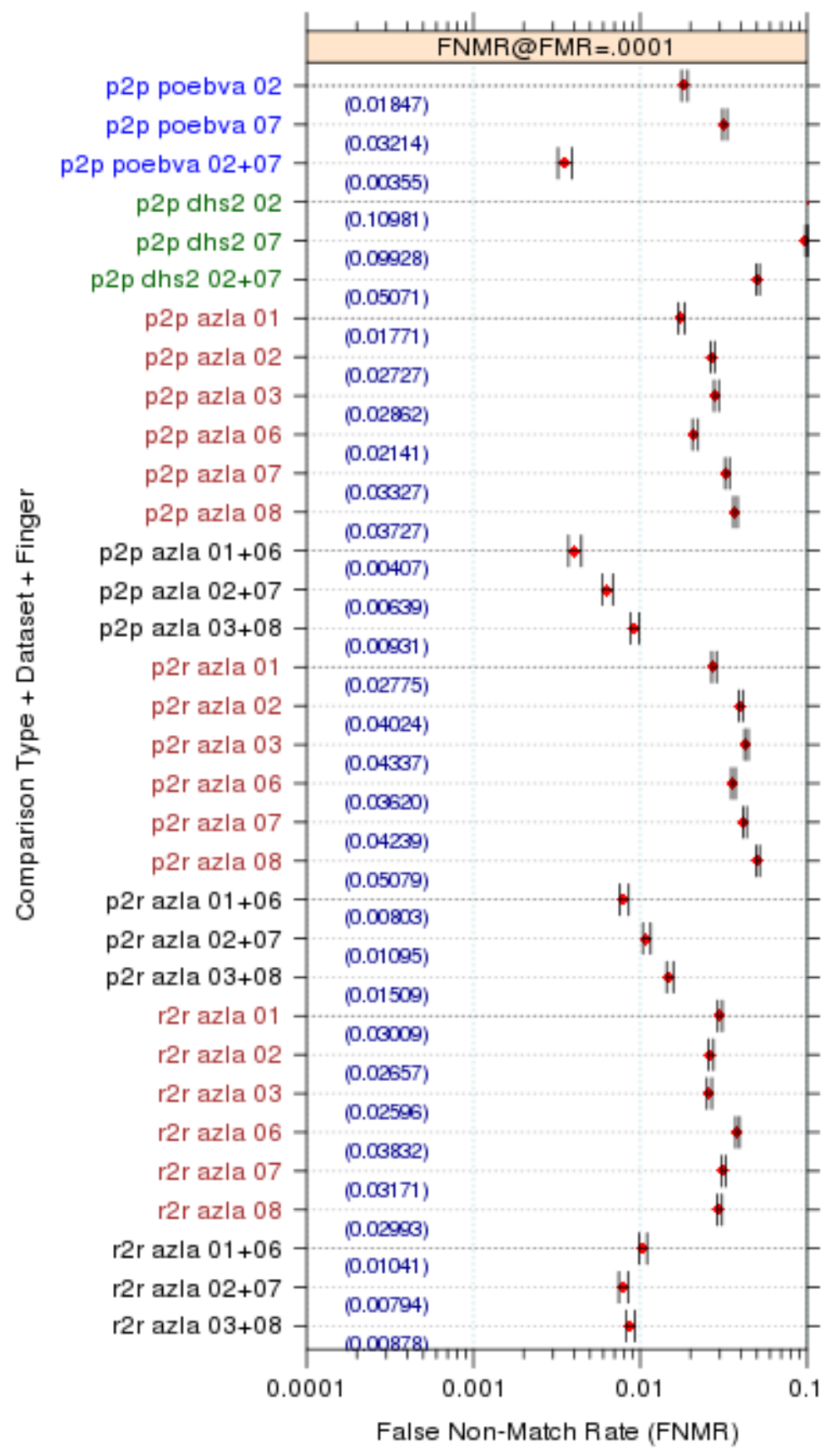

Figure 3C-3: FNMRs @ FMR = .0001 and 95\% Confidence Intervals 


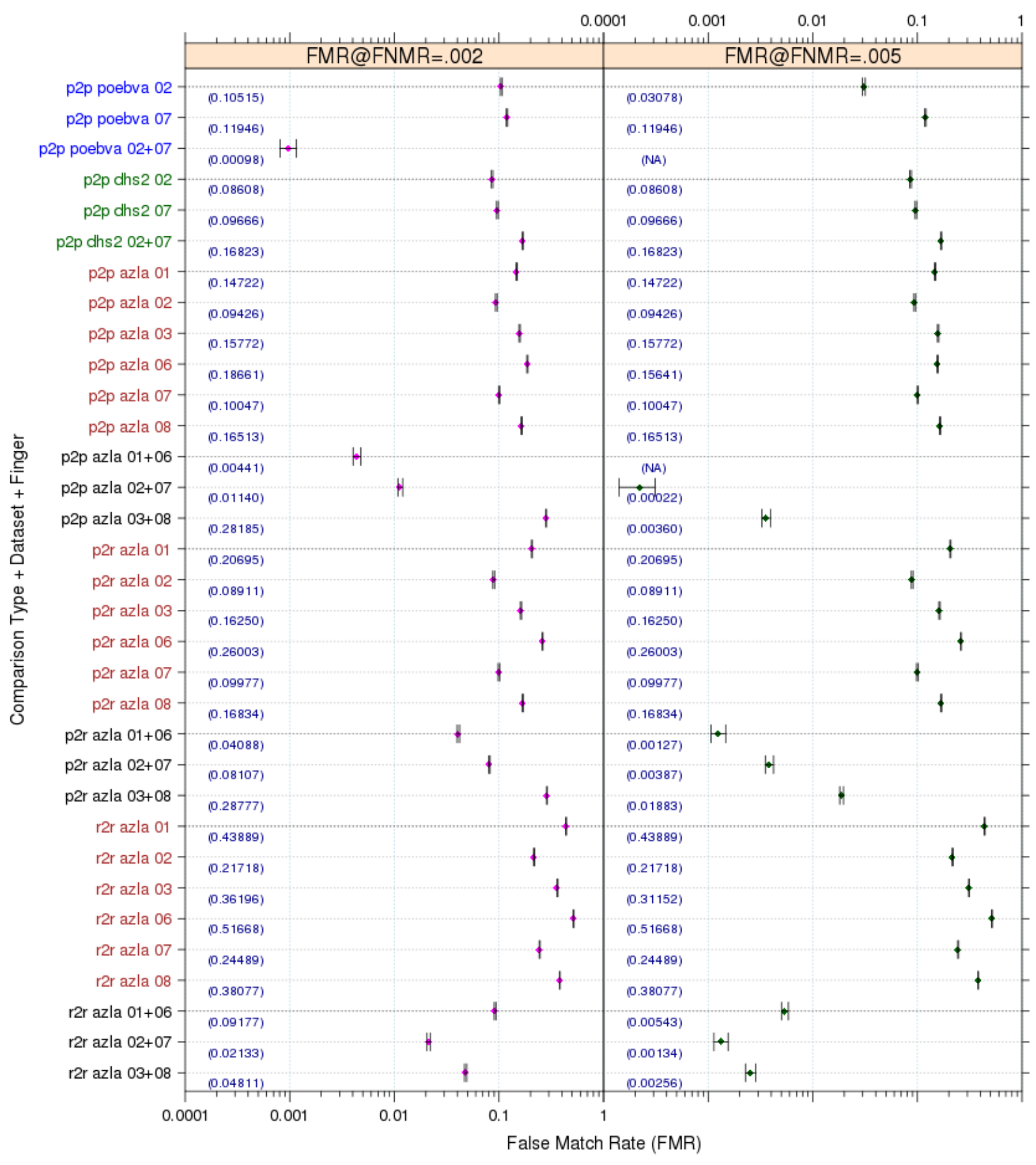

Figure 3C-7: FMRs @ FNMR = $(.002,0.005)$ and 95\% Confidence Intervals

Note: NA - The number couldn't be reliably measured with the current sample size of 120,000. 


\begin{tabular}{|c|c|c|c|c|c|}
\hline $\begin{array}{c}\text { Comparison } \\
\text { Type }\end{array}$ & Dataset & $\begin{array}{c}\text { Finger } \\
\text { Position }\end{array}$ & EER & FTE Rate & FTE count \\
\hline $\mathrm{p} 2 \mathrm{p}$ & poebva & 02 & 0.0073 & 0 & 0 \\
\hline $\mathrm{p} 2 \mathrm{p}$ & poebva & 07 & 0.0138 & 0 & 0 \\
\hline $\mathrm{p} 2 \mathrm{p}$ & poebva & $02+07$ & 0.0017 & 0 & 0 \\
\hline $\mathrm{p} 2 \mathrm{p}$ & $\mathrm{dhs} 2$ & 02 & 0.0669 & 0 & 0 \\
\hline $\mathrm{p} 2 \mathrm{p}$ & $\mathrm{dhs} 2$ & 07 & 0.0578 & 0 & 0 \\
\hline $\mathrm{p} 2 \mathrm{p}$ & $\mathrm{dhs} 2$ & $02+07$ & 0.0349 & 0 & 0 \\
\hline $\mathrm{p} 2 \mathrm{p}$ & azla & 01 & 0.0090 & 0 & 0 \\
\hline $\mathrm{p} 2 \mathrm{p}$ & azla & 02 & 0.0123 & 0 & 0 \\
\hline $\mathrm{p} 2 \mathrm{p}$ & azla & 03 & 0.0150 & 0 & 0 \\
\hline $\mathrm{p} 2 \mathrm{p}$ & azla & 06 & 0.0099 & 0 & 0 \\
\hline $\mathrm{p} 2 \mathrm{p}$ & azla & 07 & 0.0151 & 0 & 0 \\
\hline $\mathrm{p} 2 \mathrm{p}$ & azla & 08 & 0.0188 & 0 & 0 \\
\hline $\mathrm{p} 2 \mathrm{p}$ & azla & $01+06$ & 0.0023 & 0 & 0 \\
\hline $\mathrm{p} 2 \mathrm{p}$ & azla & $02+07$ & 0.0029 & 0 & 0 \\
\hline $\mathrm{p} 2 \mathrm{p}$ & azla & $03+08$ & 0.0048 & 0 & 0 \\
\hline $\mathrm{p} 2 \mathrm{r}$ & azla & 01 & 0.0124 & 0 & 0 \\
\hline $\mathrm{p} 2 \mathrm{r}$ & azla & 02 & 0.0167 & 0 & 0 \\
\hline $\mathrm{p} 2 \mathrm{r}$ & azla & 03 & 0.0188 & 0 & 0 \\
\hline $\mathrm{p} 2 \mathrm{r}$ & azla & 06 & 0.0153 & 0 & 0 \\
\hline $\mathrm{p} 2 \mathrm{r}$ & azla & 07 & 0.0190 & 0 & 0 \\
\hline $\mathrm{p} 2 \mathrm{r}$ & azla & 08 & 0.0230 & 0 & 0 \\
\hline $\mathrm{p} 2 \mathrm{r}$ & azla & $01+06$ & 0.0038 & 0 & 0 \\
\hline $\mathrm{p} 2 \mathrm{r}$ & azla & $02+07$ & 0.0047 & 0 & 0 \\
\hline $\mathrm{p} 2 \mathrm{r}$ & azla & $03+08$ & 0.0064 & 0 & 0 \\
\hline $\mathrm{r} 2 \mathrm{r}$ & azla & 01 & 0.0138 & 0 & 0 \\
\hline $\mathrm{r} 2 \mathrm{r}$ & azla & 02 & 0.0118 & 0 & 0 \\
\hline $\mathrm{r} 2 \mathrm{r}$ & azla & 03 & 0.0122 & 0 & 0 \\
\hline $\mathrm{r} 2 \mathrm{r}$ & $\mathrm{azla}$ & 06 & 0.0159 & 0 & 0 \\
\hline $\mathrm{r} 2 \mathrm{r}$ & azla & 07 & 0.0126 & 0 & 0 \\
\hline $\mathrm{r} 2 \mathrm{r}$ & azla & 08 & 0.0135 & 0 & 0 \\
\hline $\mathrm{r} 2 \mathrm{r}$ & azla & $01+06$ & 0.0051 & 0 & 0 \\
\hline $\mathrm{r} 2 \mathrm{r}$ & azla & $02+07$ & 0.0037 & 0 & 0 \\
\hline $\mathrm{r} 2 \mathrm{r}$ & azla & $03+08$ & 0.0044 & 0 & 0 \\
\hline & & & & & 0 \\
\hline
\end{tabular}

Table 3C-3: EER, FTE and FTE Count

Note: All the FET count are 0s, Hence FTE $=0$ 


\begin{tabular}{|c|c|c|c|c|c|c|c|c|}
\hline $\begin{array}{l}\text { Matching } \\
\text { Type }\end{array}$ & Dataset & $\begin{array}{l}\text { Finger } \\
\text { position }\end{array}$ & $\begin{array}{c}\text { FNMR@ } \\
\text { FMR= } \\
0.0001\end{array}$ & $\begin{array}{c}95 \% \\
\text { Confidence } \\
\text { Interval of } \\
\text { FNMR }\end{array}$ & $\begin{array}{c}\text { FMR1 @ } \\
\text { FNMR= } \\
0.002\end{array}$ & $\begin{array}{c}95 \% \\
\text { Confidence } \\
\text { Interval of } \\
\text { FMR1 }\end{array}$ & $\begin{array}{c}\text { FMR2 @ } \\
\text { FNMR= } \\
0.005\end{array}$ & $\begin{array}{c}95 \% \\
\text { Confidence } \\
\text { Interval of } \\
\text { FMR2 }\end{array}$ \\
\hline p2p & poebva & 02 & 0.0185 & \pm 0.00076 & 0.1052 & \pm 0.00174 & 0.0308 & \pm 0.00098 \\
\hline p2p & poebva & 07 & 0.0321 & \pm 0.00100 & 0.1195 & \pm 0.00184 & 0.1195 & \pm 0.00184 \\
\hline p2p & poebva & $02+07$ & 0.0036 & \pm 0.00034 & 0.0010 & \pm 0.00018 & NA & NA \\
\hline p2p & dhs2 & 02 & 0.1098 & \pm 0.00177 & 0.0861 & \pm 0.00159 & 0.0861 & \pm 0.00159 \\
\hline p2p & dhs2 & 07 & 0.0993 & \pm 0.00169 & 0.0967 & \pm 0.00167 & 0.0967 & \pm 0.00167 \\
\hline p2p & dhs2 & $02+07$ & 0.0507 & \pm 0.00124 & 0.1682 & \pm 0.00212 & 0.1682 & \pm 0.00212 \\
\hline p2p & azla & 01 & 0.0177 & \pm 0.00075 & 0.1472 & \pm 0.00201 & 0.1472 & \pm 0.00201 \\
\hline p2p & azla & 02 & 0.0273 & \pm 0.00092 & 0.0943 & \pm 0.00165 & 0.0943 & \pm 0.00165 \\
\hline p2p & azla & 03 & 0.0286 & \pm 0.00094 & 0.1577 & \pm 0.00206 & 0.1577 & \pm 0.00206 \\
\hline p2p & azla & 06 & 0.0214 & \pm 0.00082 & 0.1866 & \pm 0.00220 & 0.1564 & \pm 0.00206 \\
\hline p2p & azla & 07 & 0.0333 & \pm 0.00102 & 0.1005 & \pm 0.00170 & 0.1005 & \pm 0.00170 \\
\hline p2p & azla & 08 & 0.0373 & \pm 0.00107 & 0.1651 & \pm 0.00210 & 0.1651 & \pm 0.00210 \\
\hline p2p & azla & $01+06$ & 0.0041 & \pm 0.00036 & 0.0044 & \pm 0.00038 & NA & NA \\
\hline p2p & azla & $02+07$ & 0.0064 & \pm 0.00045 & 0.0114 & \pm 0.00060 & 0.0002 & \pm 0.00009 \\
\hline p2p & azla & $03+08$ & 0.0093 & \pm 0.00054 & 0.2819 & \pm 0.00255 & 0.0036 & \pm 0.00034 \\
\hline $\mathrm{p} 2 \mathrm{r}$ & azla & 01 & 0.0278 & \pm 0.00093 & 0.2070 & \pm 0.00229 & 0.2070 & \pm 0.00229 \\
\hline $\mathrm{p} 2 \mathrm{r}$ & azla & 02 & 0.0402 & \pm 0.00111 & 0.0891 & \pm 0.00161 & 0.0891 & \pm 0.00161 \\
\hline $\mathrm{p} 2 \mathrm{r}$ & azla & 03 & 0.0434 & \pm 0.00115 & 0.1625 & \pm 0.00209 & 0.1625 & \pm 0.00209 \\
\hline $\mathrm{p} 2 \mathrm{r}$ & azla & 06 & 0.0362 & \pm 0.00106 & 0.2600 & \pm 0.00248 & 0.2600 & \pm 0.00248 \\
\hline $\mathrm{p} 2 \mathrm{r}$ & azla & 07 & 0.0424 & \pm 0.00114 & 0.0998 & \pm 0.00170 & 0.0998 & \pm 0.00170 \\
\hline$p 2 r$ & azla & 08 & 0.0508 & \pm 0.00124 & 0.1683 & \pm 0.00212 & 0.1683 & \pm 0.00212 \\
\hline $\mathrm{p} 2 \mathrm{r}$ & azla & $01+06$ & 0.0080 & \pm 0.00051 & 0.0409 & \pm 0.00112 & 0.0013 & \pm 0.00020 \\
\hline $\mathrm{p} 2 \mathrm{r}$ & azla & $02+07$ & 0.0110 & \pm 0.00059 & 0.0811 & \pm 0.00154 & 0.0039 & \pm 0.00035 \\
\hline $\mathrm{p} 2 \mathrm{r}$ & azla & $03+08$ & 0.0151 & \pm 0.00069 & 0.2878 & \pm 0.00256 & 0.0188 & \pm 0.00077 \\
\hline $\mathrm{r} 2 \mathrm{r}$ & azla & 01 & 0.0301 & \pm 0.00097 & 0.4389 & \pm 0.00281 & 0.4389 & \pm 0.00281 \\
\hline $\mathrm{r} 2 \mathrm{r}$ & azla & 02 & 0.0266 & \pm 0.00091 & 0.2172 & \pm 0.00233 & 0.2172 & \pm 0.00233 \\
\hline$r 2 r$ & azla & 03 & 0.0260 & \pm 0.00090 & 0.3620 & \pm 0.00272 & 0.3115 & \pm 0.00262 \\
\hline $\mathrm{r} 2 \mathrm{r}$ & azla & 06 & 0.0383 & \pm 0.00109 & 0.5167 & \pm 0.00283 & 0.5167 & \pm 0.00283 \\
\hline $\mathrm{r} 2 \mathrm{r}$ & azla & 07 & 0.0317 & \pm 0.00099 & 0.2449 & \pm 0.00243 & 0.2449 & \pm 0.00243 \\
\hline$r 2 r$ & azla & 08 & 0.0299 & \pm 0.00096 & 0.3808 & \pm 0.00275 & 0.3808 & \pm 0.00275 \\
\hline$r 2 r$ & azla & $01+06$ & 0.0104 & \pm 0.00057 & 0.0918 & \pm 0.00163 & 0.0054 & \pm 0.00042 \\
\hline$r 2 r$ & azla & $02+07$ & 0.0079 & \pm 0.00050 & 0.0213 & \pm 0.00082 & 0.0013 & \pm 0.00021 \\
\hline $\mathrm{r} 2 \mathrm{r}$ & azla & $03+08$ & 0.0088 & \pm 0.00053 & 0.0481 & \pm 0.00121 & 0.0026 & \pm 0.00029 \\
\hline
\end{tabular}

\section{Table 3C-4: FMRs @ FNMR $=\{.002,0.005\}$ and 95\% Confidence Intervals}

Note: NA - The number couldn't be reliably measured with the current sample size of 120,000 .

\footnotetext{
$3 A=$ Avalon Biometrics S.L. $\quad 3 B=I D$ Solutions, Inc.

$3 C=$ Patrima Technology Company
} 


\section{Appendix - B}

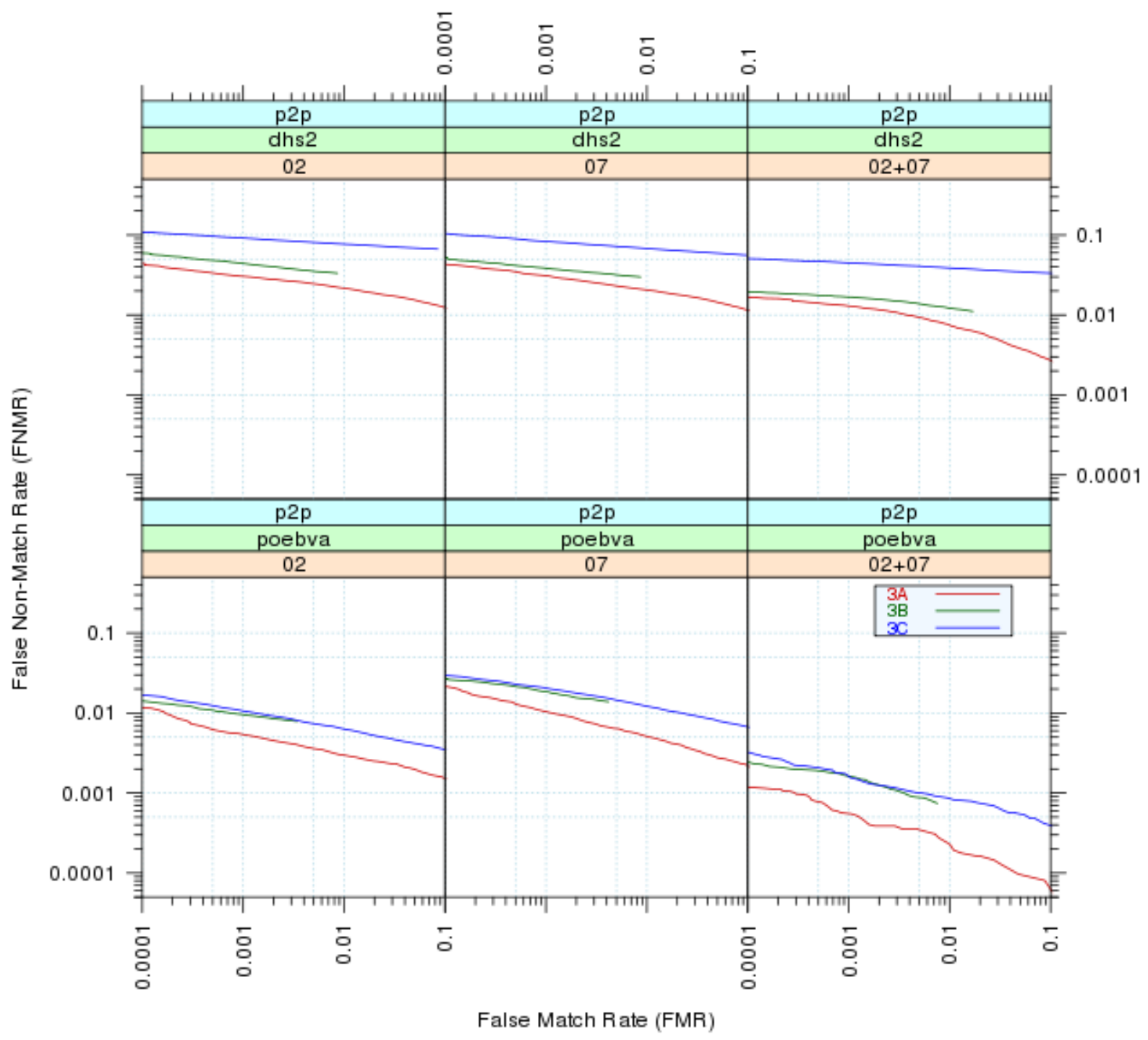

Figure 9: FNMR vs. FMR from DHS2 and POEBVA of PFT sample for Plain vs. Plain Comparison by Right index, Left index, and two index fingers fusion.

\begin{tabular}{|c|c|c|c|c|c|c|c|}
\hline \multicolumn{2}{|c|}{ Plain vs. Plain } & \multicolumn{6}{c|}{ FNMR } \\
\hline SDK & Dataset & \multicolumn{3}{|c|}{ FMR $=0.0001$} & \multicolumn{3}{c|}{ FMR $=0.001$} \\
\hline & & 02 & 07 & $02+07$ & 02 & 07 & $02+07$ \\
\hline 3A & dhs2 & 0.0434 & 0.0430 & 0.0166 & 0.0304 & 0.0310 & 0.0130 \\
\hline 3B & dhs2 & 0.0600 & 0.0516 & 0.0195 & 0.0445 & 0.0388 & 0.0168 \\
\hline 3C & dhs2 & 0.1089 & 0.1041 & 0.0508 & 0.0914 & 0.0833 & 0.0448 \\
\hline 3A & poebva & 0.0117 & 0.0215 & 0.0012 & 0.0054 & 0.0104 & 0.0006 \\
\hline 3B & poebva & 0.0140 & 0.0267 & 0.0025 & 0.0096 & 0.0185 & 0.0017 \\
\hline 3C & poebva & 0.0167 & 0.0293 & 0.0032 & 0.0107 & 0.0204 & 0.0016 \\
\hline
\end{tabular}

Table 1: FNMR at FMR $=\{0.0001,0.001\}$
$3 \mathrm{~A}=$ Avalon Biometrics S.L.
$3 B=$ ID Solutions, Inc.
$3 \mathrm{C}=$ Patrima Technology Company 